\title{
FDI in Post-Production Services and Product Market Competition
}

\author{
Jota Ishikawa ${ }^{\mathrm{a}, *}$, Hodaka Morita $^{\mathrm{b}}$, Hiroshi Mukunoki ${ }^{\mathrm{c}}$ \\ ${ }^{a}$ Faculty of Economics, Hitotsubashi University, Kunitachi, Tokyo 186-8601, Japan \\ ${ }^{b}$ School of Economics, Australian School of Business, The University of New South Wales, Sydney 2052, Australia \\ ${ }^{c}$ Faculty of Economics, Gakushuin University, Mejiro 1-5-1, Toshima-ku, Tokyo 187-0031, Japan
}

\begin{abstract}
Post-production services, such as sales, distribution, and maintenance, comprise a crucial element of business activity. We explore an international duopoly model in which a foreign firm has the option of outsourcing post-production services to its domestic rival or providing those services by establishing its own facilities through FDI. We demonstrate that trade liberalization in goods may hurt domestic consumers and lower world welfare, and that the negative welfare impacts are turned into positive ones if service FDI is also liberalized. This finding yields important policy implications, given the reality that the progress of liberalization in service sectors is still limited.
\end{abstract}

Keywords:

post-production services, trade liberalization, FDI, outsourcing, international oligopoly

\section{Introduction}

Business activity does not end with the production of the final product. After production, a variety of business activities such as marketing, sales and distribution, and the provision of maintenance and repair services should be effectively carried out to maximize the value of products that have been produced. This is a widely held view in the strategic management literature. Porter (1985), for example, pointed out that firms' primary activities can be divided into inbound logistics, operations, outbound logistics, marketing and sales, and service. In Porter's classification, outbound logistics means activities associated with collecting, storing, and physically distributing the product to buyers, marketing and sales means activities associated with providing a means by which buyers can purchase the product and inducing them to do so, and service means activities associated with providing service to enhance or maintain the value of the product.

In the present paper, outbound logistics, marketing and sales, and service are together referred to as "post-production services." A crucial strategic decision that every producer of final products needs to make is whether to perform post-production services by itself or outsource (some of) them to other firms. Since proximity to customers is a crucial element for post-production services, this decision is particularly important in the context of international trade. Foreign producers often

\footnotetext{
${ }^{*}$ Corresponding author. Tel: +81-42-580-8794; Fax: +81-42-580-8882.

Email addresses: jota@econ.hit-u.ac.jp (Jota Ishikawa), H.Morita@unsw.edu.au (Hodaka Morita), hiroshi.mukunoki@gakushuin.ac.jp (Hiroshi Mukunoki)
} 
outsource post-production services to their domestic rivals. For example, automobiles manufactured by foreign auto-makers are often sold and distributed by their local rivals. ${ }^{1}$ Alternatively, foreign producers can establish local affiliates in the domestic market and perform post-production services by themselves (foreign direct investment (FDI) in post-production services). ${ }^{2}$

The objective of this paper is to analyze the provision of post-production services in the context of international trade and to explore its welfare consequences and policy implications. To this end, we explore an international duopoly model in which two firms, one domestic and the other foreign, produce differentiated products in their own countries and compete in the domestic market. Postproduction services must be performed before a product is consumed. ${ }^{3}$ The foreign firm has the option of outsourcing post-production services to its domestic rival by paying royalties or providing those services by itself in the domestic market. In the latter case, however, the foreign firm must establish its own service facilities in the domestic market by incurring a fixed cost for FDI. ${ }^{4}$

In our analysis, we take the following aspects of reality into account. Multilateral negotiations under GATT/WTO have greatly facilitated the liberalization of the trade in goods, and many countries have committed to maintain low levels of tariff rates. However, with respect to the trade in services, although the General Agreements on Trade in Services (GATS) came into effect in 1995 as a result of the GATT Uruguay Round negotiations and has been contributing toward expanding trade in services, the progress is still limited. For instance, Roy et al. (2007) reported that only 52 WTO members had made commitments to liberalizing distribution services under GATS. The limited progress means that foreign firms may still have to incur substantial extra costs for service FDI because of regulatory impediments. ${ }^{5}$ Melitz (2003), for example, pointed out that an exporting firm must set up new distribution channels in the foreign country and conform to all the shipping rules specified by the foreign customs agency, and that, although some of these costs cannot be avoided, others are often manipulated by governments. ${ }^{6,7}$ When restrictions on service FDI are high, foreign firms may have to rely on service outsourcing to perform post-production services in domestic markets. In fact, according to OECD (2001), the number of the non-equity form of new

\footnotetext{
${ }^{1}$ In the Japanese market, examples include Volkswagen-Toyota, Ford-Mazda, Volvo-Subaru, and Peugeot-Suzuki, among others. The following examples are also found in Japan. (i) Several pharmaceutical products produced by Bayer, a German firm, are sold and distributed by its Japanese rivals, Meiji Seika and Kyorin Pharmaceutical. (ii) A Japanese liquor company, Suntory, sells wines, beers, whiskies, brandies, liqueurs, and mineral waters made by foreign companies. (iii) Evian, a mineral water made by French company Danone, is distributed in Japan by a Japanese beverage company, Calpis. Also, according to Ohmae (1989), in the US pharmaceutical industry, Marion Laboratories distributes Tanabe's Herbesser and Chugai's Ulcerlmin; Merck distributes Yamanouchi's Gaster; and Eli Lilly distributes Fujisawa's Cefamezin.

${ }^{2}$ For example, in the late 1980s a number of foreign auto-makers such as BMW, Chrysler, and Mercedes-Benz established their own distribution networks in Japan.

${ }^{3}$ We focus on a class of post-production services that are indispensable for consumption of goods but do not affect demand of goods. See Section 2 for details.

${ }^{4}$ It should be emphasized that our approach is fundamentally different from the incomplete contracting approach which has been recently applied to the analysis of vertical structures in the context of international trade. For details, see the second last paragraph of this section.

${ }^{5}$ In his recent study on restrictiveness of FDI, Golub (2003) adopted "obligatory screening and approval procedures" and "restrictions on foreign ownership" as two main restrictions, and found that FDI restrictions on business and distribution services are higher than those on manufacturing.

${ }^{6}$ Melitz's argument is based on a number of interviews with managers in Colombian firms making export decisions conducted by Roberts and Tybout (1997).

${ }^{7}$ In the late 80's, Toysrus' retail establishment was delayed in Japan because of the Large-scale Retail Store Low. The United States considered that its application was arbitrary and regarded the low as a typical impediment against service FDI.
} 
cross-border alliances in business services increased from 25 in 1989 to 1097 in 2000.

In our framework, the liberalization of the trade in services reduces the fixed cost of service FDI, and the liberalization of the trade in goods reduces the tariff. The connection between production and post-production services, uniquely captured by our model, yields novel welfare consequences and policy implications as outlined below. Suppose that both the tariff rate and the fixed cost for service FDI are initially high. We demonstrate a possibility that, contrary to the conventional result, a tariff reduction hurts consumers and reduces world welfare. As in the standard analyses, the direct effect of a tariff reduction is beneficial for consumers and the foreign firm, but is harmful for the domestic firm. In our framework, however, the domestic firm can mitigate the negative effect of a tariff reduction by raising the price it charges the foreign firm for post-production services, and the higher service price works in the direction of raising goods prices. We show that, from the welfare standpoint, the latter effect can overshadow the former effect so that the tariff reduction actually hurts consumers and reduces world welfare in equilibrium.

Importantly, if the fixed cost for service FDI is also reduced, the domestic firm has less room to increase the service price in response to the tariff reduction, and a sufficient reduction of the fixed cost for service FDI converts the negative welfare effect of tariff reduction into a positive effect. In other words, the liberalization of service FDI can convert a welfare-reducing trade liberalization into a welfare-enhancing trade liberalization. Interestingly, the liberalization of service FDI improves welfare even when it does not induce the foreign firm to actually undertake service FDI. We believe that these are important policy implications, given that post-production services consist of an important subclass of services, ${ }^{8}$ and that foreign firms' difficulties in undertaking post-production services in the domestic market have been recently considered to be a serious non-tariff barrier. ${ }^{9}$

We should mention that we construct a highly stylized model to make our point in a transparent way. Our model, however, can be extended in a number of ways. For example, non-producers of the good (or, independent service organizations (ISOs)) sometimes perform post-production services for goods producers. Our model can incorporate ISOs by assuming that the foreign firm can outsource services to the domestic firm or one of the ISOs. Also, we can incorporate more than one domestic firm. We discuss the robustness of our findings under a number of alternative setups in Subsection 4.2.

Cross-border transactions of services and FDI in services have been previously studied in the trade literature. ${ }^{10}$ Recently, several papers have considered market access and distribution, an important example of post-production services, in the context of international trade. Richardson (2004) has shown in a spatial-economy model that the domestic government has an incentive to open the access to retail distribution to foreign manufacturers when tariffs can be used, but it may limit the access when trade policy is not available. Francois and Wooton (2007) assume

\footnotetext{
${ }^{8}$ Browning and Singelmann (1975), for example, classified services into distribution services, producer services, social services, and personal services, recognizing distribution services (transport, storage, retail, wholesale trade) as an important subclass of services.

${ }^{9}$ For example, in the U.S.-Japan Auto Negotiation in 1995, the U.S. government required the Japanese government to promote the dealership of imported cars by the domestic car producers. Foreign firms' profitability will surely increase if the price they have to pay to outsource post-production services in the local market is reduced. Our analysis, however, indicates that the liberalization of service FDI is equally or even more important not only for increasing foreign firms' profitability but also for benefiting domestic consumers and increasing world welfare.

${ }^{10}$ See, for example, Djajić and Kierzkowski (1989), Markusen (1989), Francois (1990), Konan and Maskus (2006), and Wong et al. (2006) for cross-border transactions of services, and Raff and von der Ruhr (2001) and Markusen et al. (2005) for FDI in services.
} 
that sales of imported goods require the domestic distribution services that are supplied under imperfect competition. They have shown that trade volumes and the level of optimal tariff are positively related to the degree of competitiveness in the service sector. In these previous models, production and distribution of goods are assumed to be conducted in different industries. Qiu (2007) has developed a model to study firms' incentives to form cross-border strategic alliances and their choice of entry modes in foreign markets. In his two-country, multi-firm model, each firm's cost of distributing its products in the foreign country is assumed to become lower when the firm forms a strategic alliance with a firm in the foreign country. It should be noted that Qiu uses the term distribution costs to represent all costs incurred after production, which are costs for post-production services in our terminology.

Our paper is related to the previous studies mentioned above in the sense that we also investigate post-production services in the context of international trade. There are, however, some fundamental differences. In our model, the foreign firm determines whether it performs post-production services by itself or outsources them to its domestic rival. This decision is made under the strategic interactions between the foreign firm and the domestic firm, and their strategic interactions in the product market and the provision of post-production services are linked in our model. This linkage, which is uniquely explored in our analysis, in turn yields novel welfare and policy implications for the liberalization of both the trade in goods and service FDI. To our knowledge, our analysis is the first attempt to examine the linkage between FDI in post-production services and product market competition.

Also, our analysis is distinctively different from the incomplete contracting approach that has been recently applied to the analyses of vertical structures in the context of international trade; see Antràs (2003, 2005); Antràs and Helpman (2004); Grossman and Helpman (2004); and Feenstra and Hanson (2005). ${ }^{11}$ Their analyses address the choice between vertical integration and the purchase of a specialized input through contractual outsourcing, where relationship-specific investments governed by incomplete contracts play a central role. In contrast, as mentioned above, we focus on the connection between production and post-production services in the context of international trade, and examine its welfare and policy implications. Given our focus, we do not address relationspecificity of investment and incompleteness of contracting.

The remainder of the paper is organized as follows: Section 2 develops an international duopoly model that captures the linkage between FDI in post-production services and product market competition, and derives the equilibrium of the model. Section 3 investigates the effects of the liberalization of trade in goods, the liberalization of FDI for post-production services, and the connection between them. Section 4 elaborates on the policy implications of our findings and explores the robustness of the results under a number of alternative setups. Section 5 summarizes the paper and offers concluding remarks, which include a discussion on the difference between post-production services and intermediate inputs in our framework. The Appendix contains proofs of lemmas and propositions.

\section{The Model}

Demands in the home country are characterized by a representative consumer who consumes non-numéraire goods as well as a numéraire good. The non-numéraire goods consist of goods $D$

\footnotetext{
${ }^{11}$ See also Spencer (2005) and Helpman (2006) for a recent survey of the literature.
} 
and $F$ which are imperfect substitutes. The numéraire good is competitively produced and freely traded between countries. The indirect utility function is given by $U\left(p_{D}, p_{F}, Y\right)=V\left(p_{D}, p_{F}\right)+Y$ where $p_{D}$ and $p_{F}$ are the prices of $\operatorname{good} D$ and good $F$ respectively, and $Y$ is the income in the domestic country. ${ }^{12}$ Let $V_{i}=\partial V\left(p_{D}, p_{F}\right) / \partial p_{i}$ and $V_{i j}=\partial^{2} V\left(p_{D}, p_{F}\right) /\left(\partial p_{i} \partial p_{j}\right)$ denote the first derivative and the second derivative of the subutility function $V\left(p_{D}, p_{F}\right)$. We assume $V_{i}<0$, $V_{i i}>0$, and $V_{i j}<0(i \neq j)$.

By the Roy's identity, the demand function of good $i(i=D, F)$ is given by $x_{i}\left(p_{D}, p_{F}\right)=-V_{i}$, where $\partial x_{i}\left(p_{D}, p_{F}\right) / \partial p_{i}=-V_{i i}<0$ and $\partial x_{i}\left(p_{D}, p_{F}\right) / \partial p_{j}=-V_{i j}>0$ hold. We also assume $\left|V_{i i}\right|>\left|V_{i j}\right|$, which implies that the own-price effect on demand is larger than the cross-price effect.

We consider an international duopoly model in which the domestic firm (firm $D$ ) and the foreign firm (firm $F$ ) engage in Bertrand competition in the domestic market. Firm $D$ and firm $F$ respectively produce good $D$ and good $F$. The unit cost of producing goods is identical across firms and constant, which is normalized to zero without loss of generality. An ad valorem tariff, $t(\geq 0)$, is imposed on imports of good $F$. Post-production services must be performed before a product is consumed. We capture this by assuming that one unit of post-production services must be performed for one unit of goods to be consumed. Note that we focus on a class of postproduction services that are indispensable for consumption of goods but do not affect demand of goods. It includes distribution and certain types of maintenance. ${ }^{13}$

To perform post-production services, firms must have service facilities in the domestic country. Assume that firm $D$ has already established its facilities to perform post-production services for good $D$ in the domestic market. Firm $D$ can also perform post-production services for good $F$ at the same unit cost $c_{S} \cdot{ }^{14}$ We assume that post-production services can be performed only by goods producers (firms $D$ and $F$ ) because of economy of scope. See Subsection 4.2 for a discussion on an extension of our model in which independent service organizations can also perform post-production services for firm $F$.

Firm $F$ can perform post-production services for good $F$ by itself with the same unit service cost $c_{S}$ by establishing local facilities for performing post-production services in the domestic market. We assume that, if firm $F$ undertakes FDI in post-production services, it incurs a fixed investment cost $K(\geq 0)$. Note that the tariff on imports is still effective even if FDI in post-production services is made, which is in contrast to "tariff-jumping" FDI in production.

In sum, we consider the following two options for firm $F$ to perform post-production services in the domestic market: (i) Service FDI: Firm $F$ performs post-production services for good $F$ by incurring a fixed cost $K$ to establish its service facilities; or (ii) Service Outsourcing: Firm $F$ outsources post-production services to firm $D$, which charges a service price (or royalty) of $r$ $(>0)$ per unit of services. We assume $K$ is sufficiently low so that firm $F$ can earn positive profit under service FDI.

\footnotetext{
${ }^{12}$ The indirect utility function is derived from a standard quasi-linear utility function given by $u\left(x_{D}, x_{F}, M\right)=$ $v\left(x_{D}, x_{F}\right)+M$ where $x_{D}$ and $x_{F}$ denote the consumption of good $D$ and that of good $F$ respectively, and $M$ is the consumption of the numéraire good.

${ }^{13}$ For example, systematic provision of maintenance services is indispensable for the usage of photocopiers. The post-production services which is considered in the paper do not include marketing, because demand of goods tends to be increasing in intensity of marketing activities.

${ }^{14}$ We assume that the fixed cost for service outsourcing is zero. The qualitative nature of our results remains unchanged under an alternative setup in which the fixed cost must be incurred by firm $D$ and/or firm $F$. The formal analysis of this case can be found in the discussion-paper version of the paper (Ishikawa et al., 2008). See also Subsection 4.2 for a discussion.
} 
We can express the operating profits of the two firms (i.e., the profit gross of the fixed cost) as

$$
\begin{aligned}
\pi_{D} & =\left[p_{D}-c_{S}\right] x_{D}\left(p_{D}, p_{F}\right)+\mu\left[r-c_{S}\right] x_{F}\left(p_{D}, p_{F}\right), \\
\pi_{F} & =\left[\frac{p_{F}}{1+t}-(1-\mu) c_{S}-\mu r\right] x_{F}\left(p_{D}, p_{F}\right),
\end{aligned}
$$

where $\mu$ is the parameter which takes $\mu=1$ if firm $F$ outsources post-production services to firm $D$ and $\mu=0$ if it chooses FDI in post-production services. Consumer surplus and domestic welfare are respectively given by $C S\left(p_{D}, p_{F}\right) \equiv V\left(p_{D}, p_{F}\right)-Y$ and $W\left(p_{D}, p_{F}\right) \equiv C S\left(p_{D}, p_{F}\right)+\pi_{D}+$ $t p_{F} x_{F}\left(p_{D}, p_{F}\right) /(1+t)$ where the last term of $W\left(p_{D}, p_{F}\right)$ represents tariff revenues. World welfare is given by $W W\left(p_{D}, p_{F}\right) \equiv W\left(p_{D}, p_{F}\right)+\pi_{F}-(1-\mu) K$. Note that world welfare includes $-(1-\mu) K$ since the fixed cost of service FDI reduces the net profit of firm $F$. Since $\partial C S\left(p_{D}, p_{F}\right) / \partial p_{i}=V_{i}<0$, an increase in $p_{i}$ hurts consumers. With respect to world welfare, since $\partial W W\left(p_{D}, p_{F}\right) / \partial p_{i}=$ $\left[p_{i}-c_{S}\right]\left(\partial x_{i} / \partial p_{i}\right)+\left[p_{j}-c_{S}\right]\left(\partial x_{j} / \partial p_{i}\right)(i \neq j)$, an increase in $p_{i}$ also lowers world welfare unless $p_{j}>p_{i}$ holds and the magnitude of the cross-price effect is sufficiently close to that of the own-price effect. ${ }^{15}$ To simplify the analysis, we consider the case where both $\partial W W\left(p_{D}, p_{F}\right) / \partial p_{D}<0$ and $\partial W W\left(p_{D}, p_{F}\right) / \partial p_{F}<0$ hold in equilibrium. ${ }^{16}$

We consider a three-stage game. The timing of the game is as follows.

[Stage 1]: Firm $D$ determines whether to offer a service price of $r(>0)$.

[Stage 2]: If $r$ is offered, firm $F$ determines whether to accept the offer. ${ }^{17}$ We assume that, if firm $F$ accepts the offer, it commits to outsourcing all post-production services for good $F$ in the domestic market. Under this assumption, we can treat two options - service FDI and service outsourcing - as distinctive alternatives. If firm $F$ rejects the offer, or if firm $D$ does not offer $r$ in Stage 1, firm $F$ undertakes FDI in post-production services.

[Stage 3]: Firms $D$ and $F$ simultaneously set prices of their own products, and then consumers make purchase decisions. We assume $\pi_{D}$ and $\pi_{F}$ are supermoduler in prices so that the prices are strategic complements.

For expositional simplicity, we adopt the following tie-breaking rules: (i) If firm $F$ is indifferent between accepting and rejecting a service price $r$ offered by firm $D$ at stage 1, firm $F$ accepts it. (ii) If firm $D$ is indifferent between offering and not offering $r$, firm $D$ does not offer it.

\subsection{Product market competition}

In this subsection, we derive the equilibria of Stage-3 subgames. The game has two Stage-3 subgames depending on decisions made at Stage 2: (i) FDI subgame: Firm $F$ undertakes FDI

\footnotetext{
${ }^{15}$ By substituting $C S\left(p_{D}, p_{F}\right),(1)$, and $(2)$ into $W W\left(p_{D}, p_{F}\right)$, world welfare becomes $W W\left(p_{D}, p_{F}\right)=$ $V\left(p_{D}, p_{F}\right)-Y+\left[p_{D}-c_{S}\right] x_{D}\left(p_{D}, p_{F}\right)+\left[p_{F}-c_{S}\right] x_{F}\left(p_{F}, p_{D}\right)-(1-\mu) K$. Since $V_{i}=-x_{i}\left(p_{D}, p_{F}\right)$ holds, we have $\partial W W\left(p_{D}, p_{F}\right) / \partial p_{i}=\left[p_{i}-c_{S}\right]\left(\partial x_{i} / \partial p_{i}\right)+\left[p_{j}-c_{S}\right]\left(\partial x_{j} / \partial p_{i}\right)(i \neq j)$.

${ }^{16}$ Since we have $\sum_{i} \partial W W\left(p_{D}, p_{F}\right) / \partial p_{i}=\sum_{i}\left[p_{i}-c_{S}\right]\left\{\left(\partial x_{i} / \partial p_{i}\right)+\left(\partial x_{j} / \partial p_{i}\right)\right]<0, \partial W W\left(p_{D}, p_{F}\right) / \partial p_{i}>0$ and $\partial W W\left(p_{D}, p_{F}\right) / \partial p_{j}>0(i \neq j)$ never hold at the same time. Even if $\partial W W\left(p_{D}, p_{F}\right) / \partial p_{i}>0(i=D$ or $F)$ holds in equilibrium, the main results of the paper would remain unchanged. That is, a tariff reduction deteriorates world welfare under a range of parameterizations, and a sufficient reduction of the fixed cost for service FDI converts the negative welfare effect of tariff reduction into a positive effect. The analysis, however, becomes much more complicated and results on world welfare presented in Lemma 1, Propositions 2 and 4 need some adjustments. See the Appendix for details.

${ }^{17}$ We simplify the analysis by assuming that the equilibrium level of $r$ is determined by firm $D$ 's take-it-or-leave-it service price offer. See Subsection 4.2 for a discussion on the robustness of our results under more general bargaining procedures in which the two firms share the surplus from service outsourcing.
} 
in post-production services at Stage 2; (ii) Outsourcing (OS) subgame: firm $F$ outsources post-production services to firm $D$ at Stage 2 .

Throughout our analysis, we assume that the market size for each good is large enough and the tariff rate $t$ is small enough so that each firm $i(=D, F)$ sells a strictly positive amount of good $i$ in the domestic market in equilibrium. We also assume that the game has a unique equilibrium in the entire range of relevant parameterizations.

\subsubsection{FDI subgame}

Let us begin with the FDI subgame, in which $\mu=0$ applies in (1) and (2). In the third stage, each firm maximizes its own profit. The Nash equilibrium in prices is obtained by solving the following first-order conditions

$$
\begin{aligned}
& \frac{\partial \pi_{D}}{\partial p_{D}}=x_{D}\left(p_{D}, p_{F}\right)+\left[p_{D}-c_{S}\right] \frac{\partial x_{D}\left(p_{D}, p_{F}\right)}{\partial p_{D}}=0 \\
& \frac{\partial \pi_{F}}{\partial p_{F}}=\frac{x_{F}\left(p_{D}, p_{F}\right)}{1+t}+\left[\frac{p_{F}}{1+t}-c_{S}\right] \frac{\partial x_{F}\left(p_{D}, p_{F}\right)}{\partial p_{F}}=0 .
\end{aligned}
$$

Denote the equilibrium prices in the FDI subgame as $\widetilde{p}_{D}\left(c_{S}, t\right)$ and $\widetilde{p}_{F}\left(c_{S}, t\right)$. The producer price of good $F$ is given by $\widetilde{p}_{F}\left(c_{S}, t\right) /(1+t)$. By substituting these prices into the demand functions, the equilibrium sales are given by $\widetilde{x}_{D}\left(c_{S}, t\right)$ and $\widetilde{x}_{F}\left(c_{S}, t\right)$. The equilibrium operating profits in the FDI subgame are given by

$$
\begin{aligned}
& \tilde{\pi}_{D}\left(c_{S}, t\right)=\left[\widetilde{p}_{D}\left(c_{S}, t\right)-c_{S}\right] \widetilde{x}_{D}\left(c_{S}, t\right), \\
& \tilde{\pi}_{F}\left(c_{S}, t\right)=\left[\frac{\widetilde{p}_{F}\left(c_{S}, t\right)}{1+t}-c_{S}\right] \widetilde{x}_{F}\left(c_{S}, t\right) .
\end{aligned}
$$

\subsubsection{OS subgame}

Next turn to the OS subgame, where $\mu=1$ applies in equations (1) and (2). In the third stage, each firm maximizes its profit with respect to its price given the service price, $r$, set by firm $D$ in the first stage. The first-order conditions become

$$
\begin{aligned}
& \frac{\partial \pi_{D}}{\partial p_{D}}=x_{D}\left(p_{D}, p_{F}\right)+\left[p_{D}-c_{S}\right] \frac{\partial x_{D}\left(p_{D}, p_{F}\right)}{\partial p_{D}}+\left[r-c_{S}\right] \frac{\partial x_{F}\left(p_{D}, p_{F}\right)}{\partial p_{D}}=0 \\
& \frac{\partial \pi_{F}}{\partial p_{F}}=\frac{x_{F}\left(p_{D}, p_{F}\right)}{1+t}+\left[\frac{p_{F}}{1+t}-r\right] \frac{\partial x_{F}\left(p_{D}, p_{F}\right)}{\partial p_{F}}=0
\end{aligned}
$$

By solving these equations, we find the equilibrium prices in the OS subgame as $\widehat{p}_{D}(r, t)$ and $\widehat{p}_{F}(r, t)$. We obtain the following lemma (see Appendix for the proof).

Lemma 1. In the equilibrium of the OS subgame, a rise in the service price increases the prices of both goods and reduces the consumer surplus and world welfare, holding the tariff rate fixed.

The logic behind the lemma can be explained as follows. Given firm F's price and the tariff rate, an increase in the service price raises firm $D$ 's profit-margin from service outsourcing. This in turn makes firm $D$ more willing to raise $p_{D}$ so that $x_{F}\left(p_{D}, p_{F}\right)$ increases. As a result, firm $D$ 's optimal price increases in its service price, $r$. Besides that, given firm $D$ 's price and the tariff rate, firm $F$ 's optimal price increases in its marginal cost, $r$. Since the prices of the two goods are 
strategic complements, the incentives to raise prices for both firms lead to higher prices for both firms.

By substituting $\widehat{p}_{D}(r, t)$ and $\widehat{p}_{F}(r, t)$ into the demand functions, the equilibrium sales are given by $\widehat{x}_{D}(r, t)$ and $\widehat{x}_{F}(r, t)$. Then, the equilibrium profits of firms are respectively expressed as

$$
\begin{aligned}
& \widehat{\pi}_{D}(r, t)=\left[\widehat{p}_{D}(r, t)-c_{S}\right] \widehat{x}_{D}(r, t)+\left[r-c_{S}\right] \widehat{x}_{F}(r, t), \\
& \widehat{\pi}_{F}(r, t)=\left[\frac{\widehat{p}_{F}(r, t)}{1+t}-r\right] \widehat{x}_{F}(r, t) .
\end{aligned}
$$

Before discussing the equilibrium of the entire game, the following property is worth noting.

Lemma 2. If $r=c_{S}, \widehat{p}_{i}(r, t)=\widetilde{p}_{i}\left(c_{S}, t\right), \widehat{x}_{i}(r, t)=\widetilde{x}_{i}\left(c_{S}, t\right)$, and $\widehat{\pi}_{i}(r, t)=\widetilde{\pi}_{i}\left(c_{S}, t\right) \quad(i=\{D, F\})$ are satisfied.

When $r=c_{S}$, the third-term of (7) disappears, and the first-order conditions in the OS subgame coincide with those in the FDI subgame. This implies that the equilibrium outcomes in both subgames become the same.

\subsection{Firm $F$ 's decision}

In this subsection, we discuss firm $F$ 's choice between service outsourcing and service FDI. If firm $F$ does not accept $r$ offered by firm $D$ (or if firm $D$ does not offer any service price), then firm $F$ 's equilibrium profit in the subsequent FDI subgame is $\tilde{\pi}_{F}\left(c_{S}, t\right)-K$, which is independent of $r$. If firm $F$ accepts the offer, its equilibrium profit in the subsequent OS subgame is $\widehat{\pi}_{F}(r, t)$. Let $\widehat{\pi}_{i, r}^{\prime}(r, t) \equiv \partial \widehat{\pi}_{i}(r, t) / \partial r(i=D, F)$. Using the envelope theorem, we have

$$
\widehat{\pi}_{F, r}^{\prime}(r, t)=-\widehat{x}_{F}(r, t)+\left[\frac{\widehat{p}_{F}(r, t)}{1+t}-r\right] \frac{\partial \widehat{x}_{F}(r, t)}{\partial p_{D}} \frac{\partial \widehat{p}_{D}(r, t)}{\partial r} .
$$

The first term, which is negative, represents the direct effect of an increase in the service price on firm F's profit in the equilibrium of the OS subgame. The second term, which is positive, represents the strategic effect meaning that a higher $r$ induces a higher $p_{D}$, which in turn increases the demand for good $F$ and then increases firm $F$ 's profit.

For expositional simplicity, we focus on the case in which the direct effect dominates the indirect effect so that $\widehat{\pi}_{F, r}^{\prime}(r, t)<0$ holds for all relevant $r$, which is true under linear demand functions for example. Analogous assumptions are typically made in the literature that considers price competition in a differentiated-oligopoly model (see Ordover et al., 1990; Chen, 2001; Chen et al., 2004, for instance). ${ }^{18}$ Given $\widehat{\pi}_{F, r}^{\prime}(r, t)<0$ for all $r$, there exists a unique $\bar{r}(>0)$ such that

$$
\widehat{\pi}_{F}(\bar{r}, t)=\widetilde{\pi}_{F}\left(c_{S}, t\right)-K \text {. }
$$

We have $\widehat{\pi}_{F}(r, t)<\widetilde{\pi}_{F}\left(c_{S}, t\right)-K$ for all $r>\bar{r}$, and hence $\bar{r}$ is the maximum acceptable service price from firm $F$ 's standpoint. ${ }^{19}$ If evaluated at $r=c_{S}$, we have $\widehat{\pi}_{F}(r, t) \geq \widetilde{\pi}_{F}\left(c_{S}, t\right)-K$ with

\footnotetext{
${ }^{18}$ We can verify that if $\partial \widehat{p}_{D}(r, t) / \partial r \leq 1, \widehat{\pi}_{F, r}^{\prime}(r, t)<0$ always holds. For instance, when demand functions are linear, $\partial \widehat{p}_{D}(r, t) / \partial r<1$ necessarily holds. If $\partial \widehat{p}_{D}(r, t) / \partial r>1$, on the other hand, we can verify that $\widehat{\pi}_{F, r}^{\prime}(r, t)<0$ holds if $\partial x_{F} / \partial p_{D}$ is sufficiently small. See Appendix for details.

${ }^{19}$ If $\widehat{\pi}_{F, r}^{\prime}(r, t)<0$ does not hold for some $r$, our results remain mostly unchanged as long as there exists a value $r^{\prime}>0$ such that $\widehat{\pi}_{F}\left(r^{\prime}, t\right)=\widetilde{\pi}_{F}\left(c_{S}, t\right)-K$ and $\widehat{\pi}_{F}(r, t)<\widetilde{\pi}_{F}\left(c_{S}, t\right)-K$ for all $r>r^{\prime}$. However, the analysis becomes complicated without providing new insights.
} 
equality if $K=0$ (see Lemma 2). This implies that $\bar{r}>c_{S}$ holds if $K>0$ and $\bar{r}=c_{S}$ holds if $K=0$. The determination of $\bar{r}$ is depicted in Figure 1, where the horizontal axis is the level of the service price and the downward-sloping curve represents $\widehat{\pi}_{F}(r, t)$. At $r=c_{S}, \widehat{\pi}_{F}(r, t)=\widetilde{\pi}_{F}\left(c_{S}, t\right)$ holds and $\bar{r}$ is determined to satisfy $\widehat{\pi}_{F}(\bar{r}, t)=\widetilde{\pi}_{F}\left(c_{S}, t\right)-K$. It is easy to confirm by the figure that $\bar{r}>c_{S}$ holds as long as $K>0$ and $\bar{r}$ approaches $c_{S}$ as $K$ approaches zero (see Lemma 5 below).

\section{[Insert Figure 1 around here]}

Let $\bar{K}$ denote the fixed cost such that $\widetilde{\pi}_{F}\left(c_{S}, t\right)=\bar{K}$ holds. We assume $K<\bar{K}$ which implies $\tilde{\pi}_{F}\left(c_{S}, t\right)-K>0$, and hence $\widehat{\pi}_{F}(\bar{r}, t)>0$. This in turn implies that each firm $i(=D, F)$ sells a strictly positive amount of good $i$ in the domestic market in the equilibrium of the OS subgame for all $r \in\left[c_{S}, \bar{r}\right]$.

\subsection{Equilibrium of the entire game}

We now derive the equilibrium of the entire game. The equilibrium is either an Outsourcing (OS) equilibrium in which firm $F$ outsources post-production services to firm $D$, or an FDI equilibrium in which firm $F$ undertakes FDI in post-production services. Using the envelope theorem, we have the effect of an increase in $r$ on firm $D$ 's equilibrium profit in the OS subgame, $\widehat{\pi}_{D, r}^{\prime}(r, t) \equiv \partial \widehat{\pi}_{D}(r, t) / \partial r$, as

$$
\widehat{\pi}_{D, r}^{\prime}(r, t)=\left[\left\{\widehat{p}_{D}(r, t)-c_{S}\right\} \frac{\partial \widehat{x}_{D}(r, t)}{\partial p_{F}}+\left(r-c_{S}\right) \frac{\partial \widehat{x}_{F}(r, t)}{\partial p_{F}}\right] \frac{\partial \widehat{p}_{F}(r, t)}{\partial r}+\widehat{x}_{F}(r, t) .
$$

An increase in $r$ raises the price of good $F$. An increase in $p_{F}$ in turn increases the sales of good $D$ and benefits firm $D$, but it decreases the sales of good $F$ and reduces the profit from performing post-production services for firm $F$. These effects are represented in the first term of the above equation. An increase in $r$ also raises the per-unit profit from post-production services, which is represented in the second term of the equation.

It is straightforward to show that $\widehat{\pi}_{D, r}^{\prime}(r, t)>0$ holds for $r \leq c_{S}$. For $r>c_{S}, \widehat{\pi}_{D, r}^{\prime}(r, t)>0$ holds only if the difference between $r$ and $c_{S}$ is not too large. In what follows, we focus our analysis on the case in which $\pi_{D, r}^{\prime}(r, t)>0$ holds for all $r \in\left(c_{S}, \bar{r}\right]$. This condition is imposed for expositional simplicity. Under this condition, if firm $D$ offers its service price so that the offer is accepted by firm $F$, firm $D$ offers the maximum acceptable price $r=\bar{r}$. If it does not hold, then firm $D$ sets $r<\bar{r}$ in the equilibrium, but our main results would remain unchanged (see Subsection 4.2 for details).

Proposition 1 below characterizes the equilibrium of the entire game.

Proposition 1. The equilibrium of the entire game is an $O S$ equilibrium if $K>0$ and an FDI equilibrium if $K=0$.

Since firm $D$ incurs no fixed costs to provide firm $F$ with post-production services, its profit in the equilibrium of the OS subgame is no worse than those in the equilibrium of the FDI subgame as long as $r \geq c_{S}$. If $K>0$, we have $\bar{r}>c_{S}$ and so $\widehat{\pi}_{D}(\bar{r}, t)>\widetilde{\pi}_{D}\left(c_{S}, t\right)$ holds. In this case, firm $D$ offers $\bar{r}$ which firm $F$ accepts, and the equilibrium of the entire game becomes an OS equilibrium. If $K=0$, on the other hand, we have $\bar{r}=c_{S}$ and so $\widehat{\pi}_{D}(\bar{r}, t)=\widetilde{\pi}_{D}\left(c_{S}, t\right)$ holds by Lemma 2. Hence, firm $D$ does not offer $r$ and the equilibrium of the entire game becomes an FDI equilibrium. 
If we introduce a fixed cost of service outsourcing which firm $D$ must incur, the equilibrium of the entire game can be an FDI equilibrium even with positive $K$. Our results would remain unchanged under this alternative setup (see Subsection 4.2 for details).

\section{Liberalization of goods trade and service FDI}

This section investigates the effects of the liberalization of trade in goods, the liberalization of FDI for post-production services, and the connection between them. In our analysis, the trade liberalization is represented by a reduction in the tariff rate, $t$, and the liberalization of service FDI is represented by a reduction in the fixed cost of service FDI, $K$. Let $t_{0} \in(0, \bar{t}]$ denote the tariff rate before the trade liberalization, and $K_{0} \in(0, \bar{K})$ denote the fixed cost of service FDI before the liberalization of service FDI. Note that proofs of lemmas and propositions are presented in the Appendix.

As mentioned in the Introduction, the trade liberalization of goods has recently made substantial progress through multilateral negotiations under GATT/WTO, while the progress of the liberalization in service sectors has been slow so far. Given this, we first investigate the effects of tariff reduction, holding $K$ fixed at the pre-liberalization level, $K_{0}$. We then investigate the effects of the liberalization of service FDI, showing that the liberalization of service FDI can convert a welfare-reducing trade liberalization into a welfare-enhancing trade liberalization. We also show that, holding the tariff rate fixed, the liberalization of service FDI unambiguously improves welfare.

We first investigate the effects of the trade liberalization on the service price in the outsourcing equilibrium. Let $\bar{r}(t)$ denote the equilibrium service price as a function of $t$, and consider the effect of a tariff reduction from $t$ to $t-\Delta$. We find that $\bar{r}(t)<\bar{r}(t-\Delta)$ holds (that is, the trade liberalization increases the equilibrium service price), if $\widehat{\pi}_{F}(\bar{r}(t), t-\Delta)>\widetilde{\pi}_{F}\left(c_{S}, t-\Delta\right)-K$ holds. Under this condition, the tariff reduction increases firm $F$ 's equilibrium profit more in the OS subgame than in the FDI subgame. Then, firm $D$ can absorb this gap by increasing the service price from $\bar{r}(t)$ to $\bar{r}(t-\Delta)$ so that firm $F$ becomes indifferent between FDI and OS (that is, $\widehat{\pi}_{F}(\bar{r}(t-\Delta), t-\Delta)=\widetilde{\pi}_{F}\left(c_{S}, t-\Delta\right)-K$ holds $)$.

The idea mentioned above can be formalized as follows. Firm $F$ 's profit is $\widehat{\pi}_{F}(r, t)$ in the equilibrium of the OS subgame and $\widetilde{\pi}_{F}\left(c_{S}, t\right)-K$ in the equilibrium of the FDI subgame. At Stage 1 , firm $D$ charges the service price $r=\bar{r}$ at which firm $F$ is indifferent between outsourcing and not outsourcing post-production services. Hence, for any given $K \in(0, \bar{K}), \bar{r}$ is determined by $\widehat{\pi}_{F}(\bar{r}, t)=\widetilde{\pi}_{F}\left(c_{S}, t\right)-K$, which implies

$$
\frac{d \bar{r}}{d t}=\frac{\tilde{\pi}_{F, t}^{\prime}\left(c_{S}, t\right)-\widehat{\pi}_{F, t}^{\prime}(\bar{r}, t)}{\widehat{\pi}_{F, r}^{\prime}(\bar{r}, t)}
$$

where $\widetilde{\pi}_{F, t}^{\prime}\left(c_{S}, t\right) \equiv \partial \widetilde{\pi}_{F}\left(c_{S}, t\right) / \partial t$ and $\widehat{\pi}_{F, t}^{\prime}\left(c_{S}, t\right) \equiv \partial \widehat{\pi}_{F}\left(c_{S}, t\right) / \partial t$. Given $\widehat{\pi}_{F, r}^{\prime}(\bar{r}, t)<0$, the following lemma is immediate from (13).

Lemma 3. In the OS equilibrium, $d \bar{r} / d t<0$ holds if and only if $\widetilde{\pi}_{F, t}^{\prime}\left(c_{S}, t\right)-\widehat{\pi}_{F, t}^{\prime}(\bar{r}, t)>0$ holds.

Lemma 3 says that a reduction in tariff raises the equilibrium service price if and only if 


$$
\begin{aligned}
\widetilde{\pi}_{F, t}^{\prime}\left(c_{S}, t\right)- & \widehat{\pi}_{F, t}^{\prime}(\bar{r}, t)>0 \text { holds. Using }(6) \text { and (10), we find } \\
= & \underbrace{\frac{\widehat{\pi}_{F, t}^{\prime}\left(c_{S}, t\right)-\widehat{\pi}_{F, t}^{\prime}(\bar{r}, t)}{(1+t)^{2}}}_{\text {Direct effect }} \\
& +\underbrace{\left\{\left[\frac{\widetilde{p}_{F}\left(c_{S}, t\right)}{(1+t)}-c_{S}\right]\left(\frac{\partial \widetilde{x}_{F}}{\partial p_{D}}\right) \frac{\partial \widetilde{p}_{D}\left(c_{S}, t\right)}{\partial t}-\left[\frac{\widehat{p}_{F}(\bar{r}, t)}{(1+t)}-\bar{r}\right]\left(\frac{\partial \widehat{x}_{F}}{\partial p_{D}}\right) \frac{\partial \widehat{p}_{D}(\bar{r}, t)}{\partial t}\right\}}_{\text {Strategic effect }} .
\end{aligned}
$$

Note that $\widetilde{\pi}_{F, t}^{\prime}\left(c_{S}, t\right)-\widehat{\pi}_{F, t}^{\prime}(\bar{r}, t)>0$ holds if a tariff increase reduces firm $F$ 's profit more in the equilibrium of the OS subgame than in the equilibrium of the FDI subgame, holding the service price in the OS subgame fixed at $r=\bar{r}$.

Let us first hold prices and quantities fixed, and consider the direct effect of a tariff increase on the difference of firm F's profit in the two types of equilibrium. This effect is captured by the first term of the RHS of (14). A tariff increase results in a decrease in firm F's profit, where the decrement of firm $F$ 's profit is the same as the decrement of firm $F$ 's revenue. In the equilibrium of the OS subgame with the service price $r=\bar{r}$, firm $F$ 's unit cost of production is $\bar{r}$, which is greater than its unit $\operatorname{cost} c_{S}$ in the equilibrium of the FDI subgame. The higher unit cost works in the direction of making firm $F$ 's revenue smaller in the equilibrium of the OS subgame. At the same time, however, service outsourcing induces firm $D$ to charge a higher price to goods $D$ so that firm $F$ can sell more, because firm $D$ can make profit from selling services to firm $F$. In other words, service outsourcing weakens the degree of product market competition. This effect works in the direction of making firm $F$ 's revenue greater in the equilibrium of the OS subgame. When the latter effect dominates the former, firm $F$ 's revenue is higher in the equilibrium of the OS subgame than in the equilibrium of the FDI subgame. In such cases, an increase in the ad valorem tariff reduces firm $F$ 's revenue more in the OS subgame than in the FDI subgame holding prices and quantities fixed, implying that the sign of the direct effect is positive. We verify in the proof of Proposition 2 in the Appendix that the direct effect is indeed positive under a range of parameterizations in the linear demand system.

Next consider the strategic effect of a tariff increase, which is captured by the second term of the RHS of (14). A tariff increase induces an increase in firm $D$ 's price, which in turn induces firm $F$ to produce more. ${ }^{20}$ The strategic effect increases firm $F$ 's equilibrium profit, where the increment can be either larger or smaller in the OS subgame than in the FDI subgame. Hence the sign of the second term can also be positive or negative.

The sign of $\widetilde{\pi}_{F, t}^{\prime}\left(c_{S}, t\right)-\widehat{\pi}_{F, t}^{\prime}(\bar{r}, t)$ is positive if the direct effect and the strategic effect are both positive. Even if the strategic effect is negative, $\widetilde{\pi}_{F, t}^{\prime}\left(c_{S}, t\right)-\widehat{\pi}_{F, t}^{\prime}(\bar{r}, t)>0$ still holds if the direct effect is sufficiently positive. We have found, using the linear demand system, that $\widetilde{\pi}_{F, t}^{\prime}\left(c_{S}, t\right)-\widehat{\pi}_{F, t}^{\prime}(\bar{r}, t)>0$ holds in a range of parameterizations (see the proof of Proposition 2 in the Appendix). ${ }^{21}$

\footnotetext{
${ }^{20} \mathrm{~A}$ tariff increase also induces an increase in firm $F$ 's price, but its effect is zero at the margin because of the envelope theorem.

${ }^{21}$ Although $\widetilde{\pi}_{F, t}^{\prime}\left(c_{S}, t\right)-\widehat{\pi}_{F, t}^{\prime}(\bar{r}, t)>0$ may still hold even if the direct effect is negative, it can be shown that the direct effect has to be positive for $\widetilde{\pi}_{F, t}^{\prime}\left(c_{S}, t\right)-\widehat{\pi}_{F, t}^{\prime}(\bar{r}, t)$ to be positive under the linear demand. Suppose
} 
Next we consider the effects of the trade liberalization on the equilibrium goods prices. Suppose that the trade liberalization decreases the equilibrium service price (that is, suppose that $d \bar{r} / d t>$ 0 holds). Then the liberalization unambiguously reduces firm $F$ 's costs, and the lower service price means that the degree of product market competition becomes tougher. All these elements imply that the trade liberalization decreases the equilibrium prices of goods $D$ and $F$, and this in turn implies that the trade liberalization increases consumer surplus and world welfare. However, $d \bar{r} / d t<0$ can hold as mentioned above. If the trade liberalization increases the equilibrium service price, then its effects on the equilibrium goods prices become ambiguous. We obtain the following lemma.

Lemma 4. Holding $K$ fixed at $K_{0}$, there exist unique critical values $\lambda_{D}<0$ and $\lambda_{F}<0$ such that $d \widehat{p}_{i}(\bar{r}, t) / d t<0$ holds if and only if

$$
\frac{d \bar{r}}{d t}<\lambda_{i}
$$

holds, where $i=D, F$.

Lemma 4 tells us that the trade liberalization of goods increases the equilibrium goods price(s) if $d \bar{r} / d t$ is sufficiently negative. Totally differentiating $\widehat{p}_{i}(\bar{r}, t)$ with respect to $t$, we obtain

$$
\frac{d \widehat{p}_{i}(\bar{r}, t)}{d t}=\frac{\partial \widehat{p}_{i}(\bar{r}, t)}{\partial t}+\frac{\partial \widehat{p}_{i}(\bar{r}, t)}{\partial \bar{r}} \frac{d \bar{r}}{d t} .
$$

A tariff decrease directly reduces firm $F$ 's cost and this works in the direction of reducing the equilibrium goods prices (i.e., $\partial \widehat{p}_{i}(\bar{r}, t) / \partial t>0$ ). However, if $d \bar{r} / d t<0$, an induced increase in the service price works in the direction of increasing the equilibrium goods prices (i.e., $\partial \widehat{p}_{i}(\bar{r}, t) / \partial \bar{r}(d \bar{r} / d t)<$ 0 ) since it raises firm $F$ 's cost and also weakens the degree of product market competition. The former direct effect is dominated by the latter induced effect if $d \bar{r} / d t$ is sufficiently negative, implying that the trade liberalization increases the equilibrium goods price(s). More specifically, if $d \bar{r} / d t<-\left\{\partial \widehat{p}_{i}(\bar{r}, t) / \partial t\right\} /\left\{\partial \widehat{p}_{i}(\bar{r}, t) / \partial \bar{r}\right\} \equiv \lambda_{i}$, the trade liberalization of goods increases the price of good $i$ (see the proof of Lemma 4 in the Appendix).

Lemma 4 indicates that, if $K$ is fixed at $K_{0}$, a tariff reduction may harm consumers and reduce world welfare by increasing the equilibrium consumer prices. Proposition 2 formalizes this by investigating how the trade liberalization of goods, if not accompanied by the liberalization of FDI for post-production services, affects consumers, world welfare, and firms' profitability. In what follows, let $C S(K, t), W W(K, t), \pi_{D}(K, t)$, and $\pi_{F}(K, t)$, respectively, denote consumer surplus, world welfare, firm $D$ 's profit, and firm $F$ 's profit in the equilibrium of the entire game.

Proposition 2. Holding $K$ fixed at $K_{0}$, there exists a range of parameterizations in which a tariff reduction hurts consumers, deteriorates world welfare, and benefits firm D. More precisely, $\partial C S\left(K_{0}, t\right) / \partial t>0, \partial W W\left(K_{0}, t\right) / \partial t>0$, and $\partial \pi_{D}\left(K_{0}, t\right) / \partial t<0$ hold if $d \bar{r} / d t<\min \left[\lambda_{D}, \lambda_{F}\right]$ holds and only if $d \bar{r} / d t<\max \left[\lambda_{D}, \lambda_{F}\right]$ holds. Under a range of parameterizations, $d \bar{r} / d t<\min \left[\lambda_{D}, \lambda_{F}\right]$ holds.

that the demand function for good $i$ is linear and given by $x_{i}\left(p_{D}, p_{F}\right)=a-p_{i}+b p_{j}(i, j \in\{D, F\}, i \neq j)$, where $a(>0)$ and $b \in[0,1)$ respectively represent the market size and the substitutability of the two products. We can verify that there exists a value $b^{\prime} \in(0,1)$ such that the direct effect in the RHS of (14) takes a negative value and hence $\widetilde{\pi}_{F, t}^{\prime}\left(c_{S}, t\right)-\widehat{\pi}_{F, t}^{\prime}(\bar{r}, t) \leq 0$ holds for any $b \in\left[0, b^{\prime}\right]$. This means that $b \in\left(b^{\prime}, 1\right)$ is necessary for $\widetilde{\pi}_{F, t}^{\prime}\left(c_{S}, t\right)-\widehat{\pi}_{F, t}^{\prime}(\bar{r}, t)>0$ to hold. That is, $d \bar{r} / d t<0$ would hold only in the market where products are not highly differentiated and firms compete with each other relatively intensely. 
Proposition 2 tells us that a tariff reduction necessarily harms consumers, deteriorates world welfare, and benefits firm $D$, if it increases the equilibrium prices of both goods $D$ and $F$ (that is, if $\left.d \bar{r} / d t<\min \left[\lambda_{D}, \lambda_{F}\right]\right)$. Note that this condition is sufficient but not necessary. The negative welfare effects may persist when a tariff reduction increases at least one of the goods prices (that is, if $\left.d \bar{r} / d t<\max \left[\lambda_{D}, \lambda_{F}\right]\right)$. As shown in the proof of Proposition 2 in the Appendix, $d \bar{r} / d t<$ $\min \left[\lambda_{D}, \lambda_{F}\right]$ holds under a range of parameterizations in a linear demand system.

How can the negative impacts of tariff reduction be resolved? We address this question by exploring the connection between the trade liberalization of goods and the liberalization of service FDI.

Proposition 3. Take any parameterization in which $\partial C S\left(K, t_{0}\right) / \partial t>0$ and $\partial W W\left(K, t_{0}\right) / \partial t>0$ hold for some $K$. There exists a unique $K^{C S} \in(0, \bar{K}]$ such that $\partial C S\left(K, t_{0}\right) / \partial t<0$ hold for all $K \in$ $\left(0, K^{C S}\right)$, and a unique $K^{W W} \in(0, \bar{K}]$ such that $\partial W W\left(K, t_{0}\right) / \partial t<0$ hold for all $K \in\left(0, K^{W W}\right)$.

Suppose $C S\left(K, t_{0}\right) / \partial t>0$ and $\partial W W\left(K, t_{0}\right) / \partial t>0$ hold, so that a tariff reduction at $t=t_{0}$ hurts consumers and decreases world welfare. Proposition 2 tells us that these conditions hold under a range of parameterizations in which $d \bar{r} / d t$ is sufficiently negative. Proposition 3 says that these negative effects of the tariff reduction disappear and turn into positive ones when $K$ is reduced to a sufficiently low level by the liberalization of service FDI. Lemma 5 below is useful to understand the logic behind Proposition 3.

Lemma 5. The equilibrium service price $\bar{r}$ is strictly increasing in $K$ for all $K \in(0, \bar{K})$.

Recall that the equilibrium service price is determined by the condition $\widehat{\pi}_{F}(\bar{r}, t)=\widetilde{\pi}_{F}\left(c_{S}, t\right)-$ $K$ (equation (12)), where firm $F$ is indifferent between service outsourcing and FDI. Firm $F$ 's equilibrium profit in the equilibrium of the FDI subgame, $\widetilde{\pi}_{F}\left(c_{S}, t\right)-K$, is decreasing in $K$. Then, since $\widehat{\pi}_{F}(r, t)$ is decreasing in $r$, firm $D$ can charge a higher price for the post-production services as $K$ increases, resulting in the lemma.

The liberalization of service FDI decreases $K$, which in turn reduces the equilibrium service price $\bar{r}$. As $K$ approaches zero, $\bar{r}$ approaches $c_{S}$. Recall $d \bar{r} / d t=\left[\widetilde{\pi}_{F, t}^{\prime}\left(c_{S}, t\right)-\widehat{\pi}_{F, t}^{\prime}(\bar{r}, t)\right] / \widehat{\pi}_{F, r}^{\prime}(\bar{r}, t)$ (see equation (13)). As $\bar{r}$ approaches $c_{S}$, the numerator $\widetilde{\pi}_{F, t}^{\prime}\left(c_{S}, t\right)-\widehat{\pi}_{F, t}^{\prime}(\bar{r}, t)$ approaches zero while the denominator approaches $\widetilde{\pi}_{F, r}^{\prime}\left(c_{S}, t\right)<0$. Hence, $d \bar{r} / d t$ approaches zero as $\bar{r}$ approaches $c_{S}$, implying that the impact of the induced change in service price becomes negligible if $K$ becomes sufficiently small.

However, since the direct effect of trade liberalization always reduces the goods prices (i.e., $\left.\partial \widehat{p}_{i}(\bar{r}, t) / \partial t>0\right), \lambda_{i}=-\left\{\partial \widehat{p}_{i}(\bar{r}, t) / \partial t\right\} /\left\{\partial \widehat{p}_{i}(\bar{r}, t) / \partial \bar{r}\right\}(<0)$ does not approach zero as $\bar{r}$ approaches $c_{S}$. Then, when $K$ is reduced to a sufficiently low level, $d \bar{r} / d t$ becomes sufficiently close to zero so that $d \bar{r} / d t<\max \left[\lambda_{D}, \lambda_{F}\right]$ does not hold any more. Equation (16) then implies that we can always find a unique positive cut-off level of the fixed cost below which the direct effect of trade liberalization necessarily dominates the induced increase in the service price and so a tariff reduction always decreases the prices of both goods. More specifically, let $\widehat{K}>0$ and $\widehat{K}^{\prime}(>\widehat{K})$ denote the smallest level of $K$ such that $d \bar{r} / d t=\max \left[\lambda_{D}, \lambda_{F}\right]$ and $d \bar{r} / d t=\min \left[\lambda_{D}, \lambda_{F}\right]$ hold respectively. Trade liberalization increases the prices of both goods if $K>\widehat{K}^{\prime}$ holds and decreases them if $K<\widehat{K}$ holds. Figure 2 graphically represents these changes given that $d \bar{r} / d t<\min \left[\lambda_{D}, \lambda_{F}\right]$ holds at $K=K_{0}{ }^{22}$

\footnotetext{
${ }^{22}$ Figure 2 is depicted by using linear demands. With linear demands, we have the following properties:
} 


\section{[Insert Figure 2 around here]}

Proposition 3 then tells us that the negative welfare effects of tariff reduction disappears and turns into positive ones when $K$ is reduced to a sufficiently low level. ${ }^{23}$ In other words, when the difference between $\bar{r}$ and $c_{S}$ is sufficiently reduced by lowering $K$ (see Lemma 5 and Figure 1 ), the effect of tariff reduction on firm $F$ 's equilibrium profit in the OS subgame gets closer to the one in the FDI subgame. This in turn implies that there is less room for firm $D$ to raise the service price in response to the reduction in tariff, turning the negative welfare effects of tariff reduction into positive ones. This is what Proposition 3 says. Interestingly, the liberalization of service FDI can convert a welfare-reducing tariff reduction into a welfare-enhancing tariff reduction even though the reduction in $K$ does not induce firm $F$ to actually invest in service FDI in equilibrium as long as $K>0$.

Finally, we explore the effect of the liberalization of service FDI, holding the tariff rate fixed. As shown in the Appendix, we obtain the following proposition.

Proposition 4. For any given $t, C S(K, t), W W(K, t)$, and $\pi_{F}(K, t)$ are decreasing in $K$ while $\pi_{D}(K, t)$ is increasing in $K$ for all $K \in(0, \bar{K}]$.

A decrease in $K$ reduces the equilibrium service price $\bar{r}$ (see Lemma 5 ), and hence firm $F$ 's costs become lower, resulting in an increase in its profit. The lower service price also means that the degree of product market competition becomes tougher. Both of these elements imply that the liberalization of service FDI increases consumer surplus and world welfare, while it decreases firm $D$ 's equilibrium profit. It is interesting, again, to note that a reduction in $K$ yields pro-competitive consequences even though the reduction in $K$ does not induce firm $F$ to actually invest in service FDI in the equilibrium as long as $K>0$.

Firm $F$ undertakes service FDI when $K=0$. As Proposition 5 below tells us, when the liberalization of service FDI reduces $K$ down to zero, any tariff reduction has positive welfare effects.

Proposition 5. Under an FDI equilibrium, a tariff reduction necessarily benefits consumers, hurts firm $D$, and improves world welfare. More precisely, $\partial C S(K, t) / \partial t<0, \partial \pi_{D}(K, t) / \partial t>0$, and $\partial W W(K, t) / \partial t<0$ hold when $K=0$.

It should be noted that a reduction of $c_{S}$ also decreases $\bar{r}$. As a final point to this section, therefore, we compare a reduction of $K$ with a reduction of $c_{S}$ regarding their effects on resolving the negative impacts of tariff reductions. As shown in Proposition 3, a sufficient reduction of $K$ converts a welfare-reducing tariff reduction into a welfare-enhancing tariff reduction. A reduction of $K$ increases firm $F$ 's profit in the equilibrium of the FDI subgame, $\tilde{\pi}_{F}\left(c_{S}, t\right)-K$, and this in turn decreases the equilibrium service price $\bar{r}$ that is determined by $\widehat{\pi}_{F}(\bar{r}, t)=\widetilde{\pi}_{F}\left(c_{S}, t\right)-K$. As $K$ approaches zero, $\bar{r}$ approaches $c_{S}$ and so $\widetilde{\pi}_{F, t}^{\prime}\left(c_{S}, t\right)-\widehat{\pi}_{F, t}^{\prime}(\bar{r}, t)$ approaches zero. Hence there always exist strictly positive cut-off values of $K$ such that a reduction of $K$ below these values converts a welfare-reducing tariff reduction into a welfare-enhancing tariff reduction.

$\lambda_{F}<\lambda_{D}$, (ii) $\lambda_{i}$ is decreasing in $K$, (iii) $d \bar{r} / d t<0$ can hold only if $\left.(d \bar{r} / d t)\right|_{K=0}<0$ holds, (iv) $d \bar{r} / d t$ is U-shaped in $K$ given $\left.(d \bar{r} / d t)\right|_{K=0}<0$. Note that these properties are not necessary for Proposition 3.

${ }^{23}$ More precisely, Proposition 3 says that we can always find unique $K^{C S}$ and $K^{W W}$ in $K \in\left[\widehat{K}, \widehat{K}^{\prime}\right)$. See the proof of the proposition for details. 
Since a reduction of $c_{S}$ also increases $\tilde{\pi}_{F}\left(c_{S}, t\right)-K$, it has an effect similar to the effect of reduction of $K$ mentioned above. ${ }^{24}$ However, there is a difference between these effects. Although a reduction of $c_{S}$ reduces $\bar{r}$ as a reduction of $K$ does, $\bar{r}$ does not approach $c_{S}$ when $c_{S}$ approaches zero, and hence $\widetilde{\pi}_{F, t}^{\prime}\left(c_{S}, t\right)-\widehat{\pi}_{F, t}^{\prime}(\bar{r}, t)$ does not approach zero as $c_{S}$ approaches zero. Therefore, even if $c_{S}$ is reduced to zero, a welfare-reducing tariff reduction is not necessarily converted into a welfare-increasing tariff reduction, while a sufficient reduction of $K$ necessarily accomplishes such a conversion.

\section{Discussion}

When a foreign firm outsources post-production services to its domestic rival firm, the liberalization of trade in goods could raise the price for service outsourcing. The rise in the service price could hurt consumers and reduce world welfare by inducing goods prices to rise. We have demonstrated a possibility that the liberalization of trade in goods generates negative welfare effects in our framework. We have then shown that the liberalization of service FDI converts a welfare-reducing trade liberalization into a welfare-enhancing trade liberalization. In this section, we first discuss the policy implications of our results, and then explore the robustness of our results under alternative modelling choices.

\subsection{Policy implications}

Through multilateral negotiations under GATT/WTO, countries have been lowering the barriers for the trade in goods. Growing attention is now being paid to the market access of foreign firms in the service sector. The GATT Uruguay Round negotiations succeeded in establishing the framework of liberalizing cross-country transactions of services, that is, the GATS. The actual degree of liberalization, however, has been relatively small. For instance, Roy et al. (2007) reported that only 52 WTO members had made commitments to liberalizing distribution services under GATS. Under the limited progress of liberalization in the service sector, many foreign firms still face significantly high costs for service FDI, which prevent them from establishing local service facilities to perform post-production services by themselves in the local market.

In our theoretical framework, the current state of the world corresponds to a situation in which the tariff rate $t$ is reduced to a reasonably low level but the fixed cost for service FDI, $K$, is still high. The liberalization of trade in goods benefits consumers and enhances world welfare if it lowers the price for service outsourcing. Our analysis suggests, however, that policy makers should carefully access the effects of the trade liberalization if it raises the service price. In particular, if the rise in the service price induces the prices of both goods $D$ and $F$ to rise, the trade liberalization necessarily harms consumers and deteriorates world welfare. Our analysis uncovers a previously unnoticed importance of the liberalization of service FDI in its connection to the trade liberalization by showing that a sufficiently large reduction of the fixed cost for service FDI converts a welfare-reducing trade liberalization into a welfare-enhancing trade liberalization. That is, the liberalization of service FDI is important not only because it reduces per-unit costs of post-production services but also because it recovers the gains from the trade liberalization of goods for both consumers and world welfare. Therefore, making progress on the liberalization of service

\footnotetext{
${ }^{24}$ As is the effect of $r$ on $\hat{\pi}_{F}(r, t)$, we focus on the situation where the direct effect of the cost increase dominates the strategic effect so that $\partial \widetilde{\pi}_{F}\left(c_{S}, t\right) / \partial c_{S}<0$ holds.
} 
FDI under GATS is crucial to secure positive welfare consequences of the trade liberalization under GATT/WTO.

Recently, many regional trade agreements (RTAs) have established codes for the liberalization in the service sector in addition to those for the liberalization of the trade in goods. In these RTAs, some countries have undertaken further commitments on the liberalization of FDI in postproduction services on top of the existing GATS commitments. For instance, in its RTA with Australia, Thailand allows Australian firms $100 \%$ foreign equity ownership for distribution of their products, even though it limits foreign equity ownership up to $49 \%$ in its GATS distribution commitments. ${ }^{25}$ Singapore made broader commitments on the retailing of certain goods in its RTAs with the US, Australia, and Korea. Our analysis indicates that RTAs with deeper commitments towards the liberalization of service FDI are more likely to make the trade liberalization procompetitive, suggesting that the recent proliferation of RTAs may be superior to the multilateral liberalization under GATT/WTO.

We end this subsection by commenting on horizontal FDI. Since horizontal FDI in production to serve the local market 'jumps' tariffs, it has the same effect as a tariff elimination. In our model, the tariff elimination may hurt consumers and reduce world welfare if it is not accompanied by the liberalization of service FDI. Our findings therefore indicate that, to secure its positive welfare consequences, the liberalization of FDI in production should be accompanied by the liberalization of service FDI.

\subsection{Robustness}

Bargaining power: The assumption that firm $D$ makes a take-it-or-leave-it offer gives firm $D$ all the bargaining power to set the service price. In what follows we discuss the robustness of our results under more general bargaining procedures in which the two firms share the surplus from service outsourcing. Recall that, in the OS equilibrium, firm $D$ offers the maximum acceptable service price $r=\bar{r}$ at which firm $F$ is indifferent between outsourcing the post-production services and performing the services by itself. We have shown that a tariff reduction increases the equilibrium service price $\bar{r}$ (that is, $d \bar{r} / d t<0$ holds) in a range of parameterizations, and, if $d \bar{r} / d t$ is sufficiently negative, a tariff reduction hurts consumers and reduces world welfare.

If the two firms share the surplus through bargaining, the equilibrium service price, $\hat{r}$, is less than $\bar{r}$ and decreasing in firm $F$ 's bargaining power. As long as firm $D$ retains sufficiently strong bargaining power, $d \hat{r} / d t$ can still be sufficiently negative so that a reduction in the tariff harms consumers and lowers world welfare, and a reduction in $K$ through the liberalization of service FDI converts the welfare-reducing tariff reduction into a welfare-enhancing one. However, as firm $D$ 's bargaining power approaches zero, $\bar{r}$ approaches $c_{S}$ and $d \hat{r} / d t$ approaches zero. Hence, when firm $D$ 's bargaining power is sufficiently close to zero, a tariff reduction does not have the welfare-reducing effect and consequently a reduction of $K$ cannot play the role of converting the welfare-reducing trade liberalization into the welfare-enhancing one. However, as long as firm $D$ 's bargaining power is non-zero, a reduction in $K$ on top of a tariff reduction further increases consumer surplus and world welfare as in Proposition 4, and hence the liberalization of service FDI is still welfare-enhancing.

\footnotetext{
${ }^{25}$ Oman has also undertaken similar commitments in its RTA with the US. Many countries which had no GATS commitments in distribution services, such as Bahrain, Chile, Colombia, Costa Rica, Dominican Republic, El Salvador, Guatemala, Honduras, Morocco, and Nicaragua have undertaken commitments in distribution services in their RTAs with the US. See Roy et al. (2007) for details.
} 
Independent service organizations: Our model assumes that post-production services can be performed only by goods producers (firms $D$ and $F$ ) because of economy of scope. Alternatively, suppose that several independent service organizations (ISOs) can also perform post-production services for firm $F$ at constant marginal cost $c_{S}+m$. If firm $F$ rejects $r$ offered by firm $D$, firm $F$ determines whether to undertake FDI in post-production services or outsource services to an ISO. Under the latter option, the game proceeds to an "ISO subgame" where the equilibrium service price is given by $c_{S}+m$. Since outsourcing to an ISO does not weaken the product market competition, the profit function of each firm in the equilibrium of the ISO subgame coincides with that in the equilibrium of the FDI subgame. Hence, each firm's profit in the subsequent equilibrium is respectively given by $\tilde{\pi}_{D}\left(c_{S}+m, t\right)$ and $\tilde{\pi}_{F}\left(c_{S}+m, t\right)$.

Suppose $m>0$; that is, goods producers have cost advantages over the ISOs in performing post-production services because of the economy of scope. In this case, there exists a unique $\bar{r}^{\prime}$ such that $\widehat{\pi}_{F}\left(\bar{r}^{\prime}, t\right)=\widetilde{\pi}_{F}\left(c_{S}+m, t\right)$ is satisfied. Since outsourcing to firm $D$ weakens the degree of product market competition while outsourcing to the ISOs does not have such an effect, $\widehat{\pi}_{F}(r, t)>$ $\tilde{\pi}_{F}\left(c_{S}+m, t\right)$ holds when the service price is set at $r=c_{S}+m$. This implies that the maximum acceptable service price satisfies $\bar{r}^{\prime}>c_{S}+m$. By the same reason, $\widehat{\pi}_{D}(r, t)>\widetilde{\pi}_{D}\left(c_{S}+m, t\right)$ holds when $r=c_{S}+m$. Since $\widehat{\pi}_{D, r}^{\prime}(r, t)>0, \bar{r}^{\prime}>c_{S}+m$ means $\widehat{\pi}_{D}\left(\bar{r}^{\prime}, t\right)>\tilde{\pi}_{D}\left(c_{S}+m, t\right)$ holds. Consequently, firm $D$ offers $r=\bar{r}^{\prime}$ and firm $F$ accepts the offer in equilibrium. Hence, even if outsourcing to an ISO is an option, firm $F$ outsources services to firm $D$ in equilibrium as long as $m>0$ and $K>0$ hold. As in the base model, $d \bar{r}^{\prime} / d t=\left\{\widetilde{\pi}_{F, t}^{\prime}\left(c_{S}+m, t\right)-\widehat{\pi}_{F, t}^{\prime}\left(\bar{r}^{\prime}, t\right)\right\} / \widehat{\pi}_{F, r}^{\prime}\left(\bar{r}^{\prime}, t\right)<0$ holds in a range of parameterizations. Also, as in Proposition 2, a tariff reduction hurts consumers and deteriorates world welfare in a range of parameterizations under this alternative setup. ${ }^{26}$

Now consider the effects of the liberalization in service FDI given $m>0$. A reduction of $K$ changes the equilibrium service price that firm $D$ charges if it affects the value of firm $F$ 's outside option, that is, the maximum profit firm $F$ can earn if it rejects the service price firm $D$ offers. Let $K^{\prime}$ denote the cut-off level of fixed cost determined by $\widetilde{\pi}_{F}\left(c_{S}+m, t\right)=\widetilde{\pi}_{F}\left(c_{S}, t\right)-K^{\prime}$. If $K>K^{\prime}$, firm $F$ 's relevant outside option is outsourcing to an ISO rather than an FDI in services since it chooses the former upon its rejection of $r$ offered by firm $D$. Since $\widetilde{\pi}_{F}\left(c_{S}+m, t\right)$ is independent of $K$, a reduction in $K$ has no effect as long as $K>K^{\prime}$. Once $K$ is sufficiently reduced to satisfy $K \leq K^{\prime}$, however, outsourcing to an ISO is not firm $F$ 's relevant outside option any more because firm $F$ would choose service FDI if it rejects service price $r$ offered by firm $D$. This implies that, when trade the liberalization hurts consumers and reduces world welfare, the liberalization of service FDI mitigates the negative welfare effect of tariff reduction and eventually turns it into a positive effect in this alternative setup as well. Hence the qualitative nature of our results remains unchanged in the presence of ISOs as long as $m>0$.

Now suppose $m<0$. That is, ISOs have a cost advantage over the goods producers in performing post-production services. Then $\widetilde{\pi}_{F}\left(c_{S}+m, t\right)>\widetilde{\pi}_{F}\left(c_{S}, t\right)-K$ and $\widetilde{\pi}_{F}\left(c_{S}+m, t\right)>\widehat{\pi}_{F}(r, t)$ hold for all $K \geq 0$ and $r \geq c_{S}$, implying that firm $F$ outsources post-production services to an ISO at the price of $c_{S}+m$ in equilibrium for all $K \geq 0$. A tariff reduction does not have negative welfare impacts, and the liberalization of service FDI plays no roles in this case. Analogous results hold when $m=0$.

Fixed costs for service outsourcing: Firm $D$ incurs no fixed costs for performing postproduction services for firm $F$ in our model, and consequently firm $D$ 's profit in the equilibrium

\footnotetext{
${ }^{26}$ With the linear demand functions, we can verify that $d \bar{r}^{\prime} / d t<0$ always holds because $\widetilde{\pi}_{F, t}^{\prime}\left(c_{S}+m, t\right)-$ $\left.\widehat{\pi}_{F, t}^{\prime}\left(\bar{r}^{\prime}, t\right)\right\}>0$ is always satisfied.
} 
of the OS subgame is no less than its profit in the equilibrium of the FDI subgame as long as $r \geq c_{S}$. As a result, firm $F$ undertakes service FDI in the equilibrium of the entire game only if $K=0$. However, fixed costs for service outsourcing, such as costs for suitably adjusting firm $D$ 's facilities and learning details on how to effectively perform services for firm $F$ 's product, may often be non-negligible in reality.

In what follows, we discuss what happens under an alternative setup in which firm $D$ must incur a fixed cost for performing services for firm $F{ }^{27}$ As in our base model, the maximum acceptable service price $\bar{r}$ satisfies $\bar{r}>c_{S}$ when $K>0$. However, firm $D$ does not offer $r=\bar{r}$ in the equilibrium if its gain from outsourcing, $\widehat{\pi}_{D}(\bar{r}, t)-\widetilde{\pi}_{D}\left(c_{S}, t\right)$, is less than the fixed cost for service outsourcing. Hence, firm $F$ undertakes service FDI in the equilibrium even with $K>0$, if firm $D$ 's fixed cost is sufficiently high. Specifically, there exists a unique cut-off value $K^{\prime \prime}(>0)$ such that the equilibrium of the entire game is the OS equilibrium if $K^{\prime \prime}<K<\bar{K}$ and it is the FDI equilibrium if $0 \leq K \leq K^{\prime \prime}$. Our main results, however, remain mostly unchanged in this alternative setup. The only difference is that the conversion from a welfare-reducing trade liberalization to a welfareenhancing trade liberalization may not be accomplished when the equilibrium of the game is an OS equilibrium, since $K^{C S}$ and $K^{W W}$ as defined in Proposition 3 can be smaller than $K^{\prime \prime}$. Nonetheless, the conversion does happen when $K$ is reduced to a sufficiently low level.

The assumption of $\widehat{\pi}_{D, r}^{\prime}(r, t)>0$ : We have assumed that $\widehat{\pi}_{D, r}^{\prime}(r, t)>0$ holds for all $r \in\left[c_{S}, \bar{r}\right]$. If this assumption does not hold, firm $D$ will choose $r^{*}(\leq \bar{r})$ such that $\widehat{\pi}_{D, r}^{\prime}\left(r^{*}, t\right)=0$ is satisfied. In this case, we can verify that $d r^{*} / d t<0$ can hold, and a tariff reduction hurts consumers and reduces world welfare under a range of parameterizations as in our base model. ${ }^{28}$ A reduction of $K$ has no effects as long as $r^{*}<\bar{r}$ holds. Since $\bar{r}$ is increasing in $K$ while $r^{*}$ is independent of $K$, there is a unique cut-off value $K^{*}(>0)$ such that $r^{*} \geq \bar{r}$ holds if $K \leq K^{*}$. Therefore, once $K$ is reduced below $K^{*}$, firm $D$ charges $r=\bar{r}$ in the equilibrium and the subsequent analysis becomes identical to the one in the base model.

Two-part tariffs for service outsourcing: We have focused on per-unit royalties for service outsourcing by assuming that firm $D$ offers a per-unit service price $r$ to perform post-production services for firm $F$. In what follows, we discuss what would happen under an alternative setup in which firm $D$ can offer a two-part tariff $(R, r)$ where $R(\geq 0)$ denotes a fixed fee and $r$ denotes a per-unit royalty. In the OS equilibrium, firm $D$ chooses $(R, r)$ to maximize its profit $\widehat{\pi}_{D}(r, t)+R$ subject to $\widehat{\pi}_{F}(r, t)-R=\widetilde{\pi}_{F}\left(c_{S}, t\right)-K$. That is, firm $D$ chooses $(R, r)$ so that firm $F$ is indifferent between outsourcing services and performing them by itself. Let $\bar{R}(r)=\widehat{\pi}_{F}(r, t)-\left\{\tilde{\pi}_{F}\left(c_{S}, t\right)-K\right\}$ be the maximum fixed fee that firm $D$ can charge and let $\widetilde{r}$ be the solution of $\widehat{\pi}_{D, r}^{\prime}(r, t)+\partial \bar{R}(r) / \partial r=$ $\widehat{\pi}_{D, r}^{\prime}(r, t)+\widehat{\pi}_{F, r}^{\prime}(r, t)=0$. Since an increase in $r$ has a strategic effect that increases $p_{D}$ and $p_{F}$ and benefits both firms, the service price that maximizes the joint profit of the two firms satisfies $\tilde{r}>c_{S}$.

Let $\widetilde{K}$ be the fixed cost which satisfies $\bar{R}(\widetilde{r})=0$. If $K$ is high enough to satisfy $K>\widetilde{K}$, firm $D$ offers $(R, r)=(\bar{R}(\widetilde{r}), \widetilde{r})$ in the equilibrium where $\bar{R}(\widetilde{r})>0$ and $\widetilde{r}<\bar{r}$ hold. In this case, $d \widetilde{r} / d t<0$ can hold and a tariff reduction hurts consumers and lowers world welfare under a range of parameterizations as in our base model. ${ }^{29}$ As for the liberalization of service FDI, a reduction

\footnotetext{
${ }^{27}$ We obtain qualitatively the same result when firm $F$ shares the fixed cost of service outsourcing with firm $D$.

${ }^{28}$ Under the linear demand system, for instance, $d r^{*} / d t<0$ holds if $c_{S}$ is sufficiently small.

${ }^{29}$ Suppose that the demand function for good $i$ is linear and given by $x_{i}\left(p_{i}, p_{j}\right)=a-p_{i}+b p_{j}(i, j \in\{D, F\}, i \neq j)$ as in footnote 22 . Since $\lambda_{D}-\lambda_{F}=\widetilde{r}\left(4-b^{2}\right) /\left\{(3+t)\left(2+2 t+b^{2}\right)\right\}>0, \min \left[\lambda_{D}, \lambda_{F}\right]=\lambda_{F}$. By Proposition 2 , a tariff
} 
of $K$ reduces $\bar{R}(\widetilde{r})$ but it does not affect $\widetilde{r}$ when $K>\widetilde{K}$. If $K$ is reduced to satisfy $K \leq \widetilde{K}$, on the other hand, $\bar{R}(\widetilde{r})=0$ holds and it is optimal for firm $D$ to set $r=\bar{r}$. That is, firm $D$ offers $(R, r)=(0, \bar{r})$ in the equilibrium if $K \leq \tilde{K}$. Hence, a reduction of $K$ to a sufficiently low level below $\tilde{K}$ converts a welfare-reducing trade liberalization into welfare-enhancing one as in our base model. The qualitative nature of our main results, therefore, would remain unchanged under this alternative setup that incorporates two-part tariffs for service outsourcing.

Trade liberalization with endogenous FDI costs: We have explored the effects of the liberalization of goods trade and service FDI by treating the tariff rate and the fixed cost of service FDI as exogenous variables. As discussed in the Introduction, many countries have committed to maintaining low tariff rates under GATT/WTO multilateral agreements. Consequently, for many countries it is no longer possible to use tariffs as flexible policy instruments to enhance domestic welfare. In contrast, concerning service FDI, the limited progress of GATS means that countries can still manipulate the inflows of service FDI by raising the levels of regulatory impediments (see footnote 7 ). We can investigate the effects of trade liberalization (a reduction of tariff rate from $t_{0}$ to $t_{1}$ ) with endogenous FDI costs by assuming that the domestic government chooses $K$ to maximize domestic welfare under the exogenously given level of tariff rate $t$.

Suppose that, before Stage 1, the domestic government chooses the level of $K$ at Stage 0, taking the tariff rate $t$ as given. Let $K^{*}(t)$ denote the fixed cost of service FDI that the domestic government chooses to maximize domestic welfare, which is uniquely determined in the equilibrium. We can show that there exists a range of parameterizations in which the domestic government chooses $K^{*}\left(t_{0}\right)>0$ and $K^{*}\left(t_{1}\right)>0$, and $C S\left(K^{*}\left(t_{1}\right), t_{1}\right)<C S\left(K^{*}\left(t_{0}\right), t_{0}\right)$ and $W W\left(K^{*}\left(t_{1}\right), t_{1}\right)<$ $W W\left(K^{*}\left(t_{0}\right), t_{0}\right)$ hold where $0 \leq t_{1}<t_{0}$. This means that consumer surplus and world welfare can be decreased even if the domestic government can optimally adjust the level of $K$. An intuitive explanation is as follows. In response to the tariff reduction, the domestic government changes $K$ from $K^{*}\left(t_{0}\right)$ to $K^{*}\left(t_{1}\right)$ to maximize domestic welfare. Proposition 4 tells us that, holding the tariff rate fixed, the equilibrium consumer surplus is decreasing in $K$ while firm $D$ 's equilibrium profit is increasing in $K$. We also find that the equilibrium tariff revenue can be either increasing or decreasing in (or a non-monotone function of) $K$. Hence the relationship between domestic welfare and $K$ is ambiguous, and it depends on parameterizations. ${ }^{30}$ We can verify that the domestic government may increase $K$ in response to the tariff reduction, or may decrease it but not to a low enough level that guarantees welfare-improving tariff reductions. ${ }^{31}$ In such cases, the tariff reduction could hurt consumers and decrease world welfare. Under such a situation, by forcing the domestic government to reduce $K$, multilateral negotiations such as GATS can increase world welfare as well as consumer surplus, and convert the welfare-reducing trade liberalization into the welfare-enhancing one. Hence, endogenizing FDI costs do not change the qualitative nature of our results.

More than one domestic firm: We have analyzed the strategic interaction between firms $D$

reduction hurts consumers and reduces world welfare if $(\partial \widetilde{r} / \partial t)<\min \left[\lambda_{D}, \lambda_{F}\right]$. Since $\left.\left\{(\partial \widetilde{r} / \partial t)-\lambda_{F}\right\}\right|_{t=0}=-[b(2+$ b) $\left.\left(8+32 b+8 b^{2}+35 b^{3}+2 b^{4}+5 b^{5}\right) a+(1-b)\left(32+16 b+24 b^{2}+48 b^{3}+39 b^{5}-2 b^{6}+5 b^{7}\right) c_{S}\right] /\left[\left(1-b^{2}\right)\left(2+b^{2}\right)\left(4+5 b^{2}\right)^{2}\right]<0$ holds, $(\partial \widetilde{r} / \partial t)<\min \left[\lambda_{D}, \lambda_{F}\right]$ is satisfied if the initial tariff, $t$, is sufficiently small. Hence, even if two-part tariffs for service outsourcing are considered, a tariff reduction increases the service price, hurts consumer surplus, and reduces world welfare under a range of parameterizations.

${ }^{30}$ In international oligopoly models, any policy that increases foreign firms' operation costs generates strategic effects that cause rent-shifting, and hence such a policy tends to result in ambiguous welfare effects in each country.

${ }^{31}$ The formal analysis is provided in another version of the paper (Ishikawa et al., 2008). 
and $F$ by assuming that only one firm can produce the final good in the domestic country. One can consider an alternative setup in which $N(\geq 2)$ symmetric domestic firms, indexed by $D 1$, $D 2, \ldots, D N$, produce differentiated products. In the presence of more than one domestic firm, the qualitative nature of our main results remains unchanged if firm $F$ negotiates prices for service outsourcing with one domestic firm at a time in a sequential fashion. In particular, suppose that firm $F$ first negotiates with firm $D 1$ on service prices, and, if firm $F$ decides not to outsource services to firm $D 1$, then firm $F$ performs services by itself with service FDI or negotiates with firm $D 2$, and so on. ${ }^{32}$ In the product-market competition stage, $N+1$ firms compete in a Bertrand fashion under differentiated oligopoly. The alternative model has a unique pure-strategy equilibrium, which is an FDI equilibrium or an OS equilibrium, depending on parameterizations. In the OS equilibrium, the equilibrium service price $\hat{r}$ can increase as the tariff is reduced, and our main comparative statics results hold under a range of parameterizations.

Alternatively, suppose that domestic firms simultaneously offer service prices, and firm $F$ accepts one of the offers or rejects all offers. If domestic firms have different per-unit costs for performing post-production services for firm $F$, there exists a pure-strategy equilibrium in which a domestic firm offers $r=\bar{r}$ when the domestic firm's cost is substantially lower than the other domestic firms' costs. ${ }^{33}$

Non-tariff barriers: Since a tariff is a pure transfer from firm $F$ to the domestic government, a reduction in $t$ does not directly affect world welfare. Hence, a tariff reduction deteriorates world welfare whenever it increases both prices of goods $D$ and $F$. We can interpret $t$ as a proxy for non-tariff barriers rather than a tariff. Then, a reduction in $t$ results in the saving of real costs, which directly works in favor of world welfare. In this case, a reduction in $t$ may improve world welfare even if it increases both prices of the goods. Nevertheless, it can be shown that $\partial W W(K, t) / \partial t>0$ can hold under a range of parameterizations, and hence Propositions 2 and 3 hold under the alternative interpretation of $t .{ }^{34}$

Specific tariff: We have considered ad valorem tariffs, given their prevalence in the real world. In the case of specific tariffs, the burden of a tariff is proportional to the amount of sales, $x_{F}$, rather than to the revenue, $p_{F} x_{F}$. Hence, the first-term of the RHS of (14) representing the direct effect is replaced by $\widehat{x}_{F}(\bar{r}, t)-\widetilde{x}_{F}\left(c_{S}, t\right)$ in the case of specific tariffs. Since service outsourcing to firm $D$ weakens the degree of product-market competition, $\widehat{x}_{F}(\bar{r}, t)>\widetilde{x}_{F}\left(c_{S}, t\right)$ could hold. In this case, $d \bar{r} / d t<0$ holds if $\widehat{x}_{F}(\bar{r}, t)-\widetilde{x}_{F}\left(c_{S}, t\right)$ is sufficiently positive, and a tariff reduction could hurt consumers and enhance world welfare. Under linear demands, however, we can verify that $\widehat{x}_{F}(\bar{r}, t)-\widetilde{x}_{F}\left(c_{S}, t\right)<0$ always holds, and it outweighs the strategic effect. Hence, $d \bar{r} / d t>0$ always holds with both specific tariffs and linear demands.

Cournot competition: Consider an alternative setup in which firms compete against each other by choosing quantities. Suppose that, in an OS subgame, firm $D$ increases the quantity of good

\footnotetext{
${ }^{32}$ The sequential setup can be regarded as approximating the following scenario, which we feel is fairly realistic. When a foreign firm attempts to outsource post-production services to one of its domestic rivals, the foreign firm needs to identify a candidate firm by incurring search costs, and negotiate the terms of service outsourcing with the candidate. If the negotiation is unsuccessful, the firm will identify another candidate to negotiate with.

${ }^{33}$ If domestic firms must incur a fixed cost in providing services, there exists no pure strategy equilibrium when domestic firms have the identical per-unit cost (see Sharkey and Sibley, 1993). Each firm chooses the probability of offering service prices in a mixed strategy equilibrium, and the case in which only one firm offers the maximum acceptable service price $r=\bar{r}$ remains an equilibrium with a positive probability.

${ }^{34}$ In a related work, Sanna-Randaccio (1996) analyzes the effects of a removal of non-tariff barriers when an FDI in goods production is endogenously determined.
} 
$D$, holding the quantity of good $F$ fixed. This does not affect firm $D$ 's profit from performing post-production services for firm $F,\left(r-c_{S}\right) x_{F}$, since the quantity of good $F$ is fixed. Under Bertrand competition, on the other hand, an increase in the price of good $D$, holding the price of good $F$ fixed, increases $\left(r-c_{S}\right) x_{F}$, because it increases $x_{F}$. That is, unlike Bertrand competition, Cournot competition does not capture the idea that, although firm $D$ can increase the sales of its own product by adopting a more aggressive strategy, such a strategy also reduces its profit from performing services for its rival firm.

The difference mentioned above plays an important role in the determination of the sign of $d \bar{r} / d t$. Recall Lemma 3 and the discussion presented right after the lemma. In the equilibrium of the OS subgame with the service price $r=\bar{r}$, firm $F$ 's unit cost of production is $\bar{r}$, which is greater than its unit cost $c_{S}$ in the equilibrium of the FDI subgame. The higher unit cost works in the direction of making firm $F$ 's revenue smaller in the equilibrium of the OS subgame. This effect exists in the model under Cournot competition as well. In the model with Bertrand competition, there is another effect to be considered. That is, service outsourcing induces firm $D$ to charge a higher price to goods $D$ so that firm $F$ can sell more, because firm $D$ can make profit from selling services to firm $F$. This effect works in the direction of making firm $F$ 's revenue greater in the equilibrium of the OS subgame. As mentioned above, the second effect does not exist in the model with Cournot competition. This implies that the direct effect captured by the first term of the RHS of (14) is negative. ${ }^{35}$ Then $d \bar{r} / d t<0$ holds only if the strategic effect is positive and sufficiently large to overshadow the direct effect. With linear demands, we can verify that the second-term is positive but not large enough to overshadow the direct effect, implying that $d \bar{r} / d t \geq 0$ always holds under Cournot competition with linear demands. ${ }^{36}$

\section{Conclusion}

Post-production services such as sales, distribution, and maintenance consist of an important subclass of services. Although the liberalization of the trade in goods has made substantial progress through multilateral negotiations under GATT/WTO, the progress of the liberalization in the service sector has been limited so far. In this paper, we have uncovered a previously unnoticed importance of the liberalization in the service sector by exploring an international duopoly model that captures the linkage between product market competition and provision of post-production services. That is, we have found that the trade liberalization of goods may have negative welfare effects if it is not accompanied by the liberalization of service FDI.

The trade liberalization reduces trade costs, and this intensifies competition between a foreign firm and a domestic firm in the product market. At the same time, when the foreign firm outsources

${ }^{35}$ In the case of Cournot competition, the equation analogous to (14) is

$$
\begin{aligned}
& \tilde{\pi}_{F, t}^{\prime}\left(c_{S}, t\right)-\widehat{\pi}_{F, t}^{\prime}(\bar{r}, t) \\
= & \frac{\widehat{p}_{F}(\bar{r}, t) \widehat{x}_{F}(\bar{r}, t)-\widetilde{p}_{F}\left(c_{S}, t\right) \widetilde{x}_{F}\left(c_{S}, t\right)}{(1+t)^{2}} \\
& +\frac{1}{1+t}\left\{\widetilde{x}_{F}\left(c_{S}, t\right)\left(\frac{\partial \widetilde{p}_{F}}{\partial x_{D}}\right) \frac{\partial \widetilde{x}_{D}\left(c_{S}, t\right)}{\partial t}-\widehat{x}_{F}(\bar{r}, t)\left(\frac{\partial \widehat{p}_{F}}{\partial x_{D}}\right) \frac{\partial \widehat{x}_{D}(\bar{r}, t)}{\partial t}\right\},
\end{aligned}
$$

where the first term captures the direct effect and the second term captures the strategic effect.

${ }^{36}$ Under quantity competition with linear demands, the second effect still exists if firm $D$ acts as a Stackelberg leader, and $d \bar{r} / d t<0$ is possible in this case. 
post-production services, the trade liberalization may induce the domestic firm to charge a higher service price to absorb a part of the foreign firm's incremental profit due to lower trade costs. We have demonstrated that, if the foreign firm's fixed cost of service FDI is relatively high, the latter negative welfare effect may overshadow the former positive one so that the trade liberalization harms consumers and lowers world welfare in a range of parameterizations. Importantly, this negative welfare effect of the trade liberalization is mitigated and eventually turned into a positive one as service FDI is also liberalized. This is because a reduction in the fixed cost of service FDI decreases the price of service outsourcing that the foreign firm would accept.

Our analysis has therefore indicated that the liberalization of service FDI is important not only because it reduces per-unit costs of post-production services but also because it recovers gains from the trade liberalization in goods for both consumers and world welfare. Making progress on the liberalization of service FDI under GATS is crucial to secure positive welfare consequences of the trade liberalization under GATT/WTO.

We offer two final remarks to conclude the paper. First, we comment on the difference between post-production services and intermediate inputs in our framework. In our international duopoly model, the foreign firm has an option of outsourcing post-production services to its domestic rival or performing the services by itself in the domestic market. Since we focus on a class of postproduction services that are indispensable for the consumption of goods, it is possible to consider a model with an analogous logical structure in which post-production services are replaced by intermediate inputs. For example, one can consider a foreign firm that does not have the facilities to produce an intermediate input, and can suppose that the foreign firm determines whether it procures the intermediate input from its domestic rival or produces the input by building its own production facilities. ${ }^{37}$

A critical difference between our model and the alternative model with intermediate inputs is the role played by the liberalization of service FDI and its connection to the liberalization of trade in goods. Since intermediate inputs are not services but goods, service FDI has no direct effects on the foreign firm's make-or-buy decision in the alternative model. In contrast, the liberalization of service FDI plays a critical role in our framework. That is, in order to perform post-production services, the foreign firm needs to undertake service FDI and establish its own service facilities in the "domestic" market. In our analysis, the connection between production and post-production services has yielded a novel policy implication that the trade liberalization should be accompanied by the liberalization of service FDI to secure its positive welfare effects. The recent progress of the trade liberalization is not yet accompanied by the sufficient progress of the liberalization of service FDI, and this reality has motivated us to study the connection between production and post-production services in international contexts. Also, since the trade liberalization of goods affects the intermediate-good market as well as the final-good market, policy implications of the trade liberalization may be different between the model with intermediate inputs and the model with post-production services.

Second, given that imperfect competition in the product market is an important element of our analysis, one may argue that strengthening product market competition could be a substitute

\footnotetext{
${ }^{37}$ To the best of our knowledge, international oligopoly models with intermediate inputs as mentioned above (in which a firm decides whether or not to establish its own facilities to produce intermediate inputs) have not been previously explored. Chen et al. (2004) presented a related analysis, but firms have their own facilities to produce intermediate inputs in their model. The focus of their analysis is the comparison between the effect of the trade liberalization of intermediate goods and the effect of the trade liberalization of final goods.
} 
for liberalizing service FDI. Suppose that the domestic government has stimulated competition in the product market by inducing firms' entry, and consequently there are $N(\geq 2)$ domestic firms. As we discussed in Subsection 4.2, the liberalization of service FDI can still be critical in recovering gains from the trade liberalization of goods, as long as the price for service outsourcing is determined by one-to-one negotiations. Also, although the domestic government could induce the entry of some independent service organizations, the liberalization of service FDI could still be critical as discussed in Subsection 4.2.

There are several directions of related research that are left for future work. One direction concerns the nature of post-production services. That is, although we have focused on a class of post-production services that are indispensable for the consumption of goods but do not affect the demand for goods, it is also important to consider another class of post-production services such as marketing and repair services that affect the demand for goods. Also, another promising direction of future research seems to be empirical works that investigate the relationship between trade liberalization in goods and liberalization in service sectors. ${ }^{38}$

\section{Acknowledgements}

We wish to thank Jim Rauch and two anonymous referees for insightful comments that have helped us improve the quality of the paper. We thank Pol Antrás, Richard Baldwin, Jay Pil Choi, Masahiro Endoh, Taiji Furusawa, Seiichi Katayama, Kazuharu Kiyono, Hiroshi Kurata, Jim Markusen, Tomoya Mori, Toshihiro Matsumura, Noriaki Matsushima, Dan Sasaki, participants of seminars at Hitotsubashi University, Kobe University, Kyoto University, University of British Columbia, University of New South Wales, University of Tokyo, and participants at the APTS 2007 Meeting, the EARIE 2007 Meeting, the Otago Workshop 2008, and Hitotsubashi COE Conference on International Trade and FDI 2008 for their helpful comments and suggestions on earlier versions of this paper, and Tomohiro Ara for able research assistance. The usual disclaimer applies. Ishikawa and Morita acknowledge financial support from the Ministry of Education, Culture, Sports, Science and Technology of Japan (MEXT) under the Center of Excellence Projects and the Australian Research Council. Mukunoki acknowledges financial support by the Grant-in-Aid for Young Scientists (B), the MEXT

\section{Appendix A.}

\section{Appendix A.1. Proof of Lemma 1}

Differentiating (7) and (8) with respect to $p_{i}(i=\{D, F\})$ and $r$, and using the envelope theorem, we have

$$
\left(\begin{array}{cc}
\partial^{2} \pi_{D} /\left(\partial p_{D}\right)^{2} & \partial^{2} \pi_{D} /\left\{\partial p_{F} \partial p_{D}\right\} \\
\partial^{2} \pi_{F} /\left\{\partial p_{D} \partial p_{F}\right\} & \partial^{2} \pi_{F} /\left(\partial p_{F}\right)^{2}
\end{array}\right)\left(\begin{array}{c}
d p_{D} \\
d p_{F}
\end{array}\right)=\left(\begin{array}{r}
-\partial x_{F} / \partial p_{D} \\
\partial x_{F} / \partial p_{F}
\end{array}\right) d r
$$

The second-order sufficient conditions of profit maximization require $\partial^{2} \pi_{i} /\left(\partial p_{i}\right)^{2}<0(i=\{D, F\})$ and $\Omega \equiv\left\{\partial^{2} \pi_{D} /\left(\partial p_{D}\right)^{2}\right\}\left\{\partial^{2} \pi_{F} /\left(\partial p_{F}\right)^{2}\right\}-\left\{\partial \pi_{D} /\left(\partial p_{F} \partial p_{D}\right)\right\}\left\{\partial \pi_{F} /\left(\partial p_{D} \partial p_{F}\right)\right\}>0$. Since we consider the case where the price settings of the two firms are strategic complements, $\partial^{2} \pi_{i} /\left(\partial p_{j} \partial p_{i}\right)>0$

\footnotetext{
${ }^{38}$ By using EU data, Francois et al. (2009) find that the impact of the border price changes on consumer prices, which are partly induced by tariff changes, varies substantially across EU countries. They suggest that the variation of price impact is associated with the market structure in the retail and distribution sectors.
} 
$(i \neq j)$ holds. We assume $\left|\partial^{2} \pi_{i} /\left(\partial p_{i}\right)^{2}\right|>\partial^{2} \pi_{i} /\left(\partial p_{j} \partial p_{i}\right)$ to ensure the uniqueness of the equilibrium. By using these conditions, the effects of an increase in $r$ on the equilibrium goods prices are given by

$$
\begin{aligned}
\frac{\partial \widehat{p}_{D}(r, t)}{\partial r} & =-\frac{1}{\Omega}\left[\frac{\partial^{2} \pi_{F}}{\left(\partial p_{F}\right)^{2}} \frac{\partial x_{F}}{\partial p_{D}}+\frac{\partial^{2} \pi_{D}}{\partial p_{F} \partial p_{D}} \frac{\partial x_{F}}{\partial p_{F}}\right]>0, \\
\frac{\partial \widehat{p}_{F}(r, t)}{\partial r} & =\frac{1}{\Omega}\left[\frac{\partial^{2} \pi_{D}}{\left(\partial p_{D}\right)^{2}} \frac{\partial x_{F}}{\partial p_{F}}+\frac{\partial^{2} \pi_{F}}{\partial p_{D} \partial p_{F}} \frac{\partial x_{F}}{\partial p_{D}}\right]>0 .
\end{aligned}
$$

Since $C S\left(p_{D}, p_{F}\right)$ and $W W\left(p_{D}, p_{F}\right)$ are decreasing in each price, an increase in the service price reduces both consumer surplus and world welfare.

Appendix A.2. The condition for $\hat{\pi}_{F, r}^{\prime}<0$

Substituting (8) into (11), we have

$$
\widehat{\pi}_{F, r}^{\prime}(r, t)=\left[\frac{p_{F}}{1+t}-r\right]\left[(1+t) \frac{\partial x_{F}}{\partial p_{F}}+\frac{\partial p_{F}}{\partial r} \frac{\partial x_{F}}{\partial p_{D}}\right] .
$$

If $\partial p_{F} / \partial r \leq 1$ holds, then

$$
\widehat{\pi}_{F, r}^{\prime}(r, t) \leq\left[\frac{p_{F}}{1+t}-r\right]\left[(1+t) \frac{\partial x_{F}}{\partial p_{F}}+\frac{\partial x_{F}}{\partial p_{D}}\right]<0
$$

is satisfied, because $\partial x_{F} / \partial p_{F}<0$ and $\left|\partial x_{F} / \partial p_{F}\right|>\left|\partial x_{F} / \partial p_{D}\right|$. If $\partial p_{F} / \partial r>1$ holds, on the other hand, it is known from (A.2) that $\partial p_{F} / \partial r$ becomes smaller as $\partial x_{F} / \partial p_{D}$ becomes smaller. Besides that, given $\partial p_{F} / \partial r$ being constant, $\widehat{\pi}_{F, r}^{\prime}(r, t)<0$ holds if $\partial x_{F} / \partial p_{D}$ is sufficiently small. In this case, therefore, $\widehat{\pi}_{F, r}^{\prime}(r, t)<0$ holds if $\partial x_{F} / \partial p_{D}$ is sufficiently small.

\section{Appendix A.3. Proof of Lemma 4}

$>$ From $(16), d \widehat{p}_{i}(\bar{r}, t) / d t<0$ holds if and only if

$$
\frac{d \bar{r}}{d t}<-\frac{\partial \widehat{p}_{i}(\bar{r}, t) / \partial t}{\partial \widehat{p}_{i}(\bar{r}, t) / \partial \bar{r}} \equiv \lambda_{i}
$$

is satisfied. Differentiating (7) and (8) with respect to $p_{i}(i=\{D, F\})$ and $t$, and using the envelope theorem, we have

$$
\begin{aligned}
\frac{\partial \widehat{p}_{D}(\bar{r}, t)}{\partial t} & =-\frac{\bar{r}}{(1+t) \Omega} \frac{\partial^{2} \pi_{D}}{\partial p_{F} \partial p_{D}} \frac{\partial x_{F}}{\partial p_{F}}>0, \\
\frac{\partial \widehat{p}_{F}(\bar{r}, t)}{\partial t} & =\frac{\bar{r}}{(1+t) \Omega} \frac{\partial^{2} \pi_{D}}{\left(\partial p_{D}\right)^{2}} \frac{\partial x_{F}}{\partial p_{F}}>0 .
\end{aligned}
$$

Since $\partial \widehat{p}_{i}(\bar{r}, t) / \partial \bar{r}>0$ is also satisfied, $\lambda_{i}(i=D, F)$ is always negative. 


\section{Appendix A.4. Proof of Proposition 2}

We first note that consumer surplus and world welfare are decreasing in both $p_{D}$ and $p_{F}$, and that changes in $t$ and $r$ affect consumer surplus and world welfare only through the induced changes in $p_{D}$ and $p_{F}$. With respect to $\pi_{D}$, it is increasing in $p_{D}, p_{F}$, and $r$, while $t$ affects $\pi_{D}$ only through its induced effects on the goods prices. In view of Lemma 4 , if $d \bar{r} / d t<\min \left[\lambda_{D}, \lambda_{F}\right](<0)$ holds and a tariff reduction increases both goods prices $\left(\partial p_{D} / \partial t<0\right.$ and $\left.\partial p_{F} / \partial t<0\right)$, then $\partial C S(K, t) / \partial t>0$, $\partial C S(K, t) / \partial t>0$, and $\partial \pi_{D}(K, t) / \partial t<0$ always hold. Conversely, if $\partial C S(K, t) / \partial t>0$ and $\partial W W(K, t) / \partial t>0$ hold, it is necessary that a tariff reduction increases at least one of the goods prices. Lemma 4 suggests that $\partial p_{D} / \partial t<0$ or $\partial p_{F} / \partial t<0$ holds only if $d \bar{r} / d t<\max \left[\lambda_{D}, \lambda_{F}\right]$ holds. With respect to $\partial \pi_{D}(K, t) / \partial t$, it can be negative even if $d \bar{r} / d t \geq \max \left[\lambda_{D}, \lambda_{F}\right]$ holds, since an increase in the service price caused by a tariff reduction directly increases the profit of firm $D$.

To prove that $d \bar{r} / d t<\min \left[\lambda_{D}, \lambda_{F}\right]$ can hold under a range of parameterizations, we provide a numerical example with linear demands. We consider a specific form of the subutility function given by $V\left(p_{D}, p_{F}\right)=\bar{V}-a\left(p_{D}+p_{F}\right)+\left\{\left(p_{F}\right)^{2}+\left(p_{D}\right)^{2}\right\} / 2-b p_{D} p_{F}$ where $\bar{V}$ is a positive constant. With this function, the demand function for good $i$ is derived as $x_{i}\left(p_{D}, p_{F}\right)=a-p_{i}+b p_{j}(i, j \in\{D, F\}$, $i \neq j$ ) where $a(>0)$ and $b \in[0,1)$ respectively represent the market size and the substitutability of the two products. As $b$ gets closer to one, similarity between the two products increases. With the linear demand functions, we can verify that $\widehat{\pi}_{F, r}^{\prime}(\bar{r}, t)<0$ always holds. We can also calculate that $\lambda_{F}-\lambda_{D}=-\left(4-b^{2}\right) \bar{r} /\left\{(3+t)\left(2+2 t+b^{2}\right)\right\}<0$. Hence, to prove $d \bar{r} / d t<\min \left[\lambda_{D}, \lambda_{F}\right]$ can hold, it is sufficient to prove $d \bar{r} / d t<\lambda_{F}$ holds under a range of parameterizations. Suppose $a=10$, $b=0.9, c_{S}=1, t=0.1$, and $K_{0}=4$. Then with these parameterizations, the sales of good $F$ is positive, $\pi_{D, r}^{\prime}(r, t)>0$ holds for all $r \in\left(c_{S}, \bar{r}\right], K_{0}<\bar{K}$ is satisfied, and $\partial W W\left(p_{D}, p_{F}\right) / \partial p_{D}<0$ and $\partial W W\left(p_{D}, p_{F}\right) / \partial p_{F}<0$ hold. We can calculate that $\widehat{p}_{F}(\bar{r}, t) \widehat{x}_{F}(\bar{r}, t)-\widetilde{p}_{F}\left(c_{S}, t\right) \widetilde{x}_{F}\left(c_{S}, t\right) \approx$ 10.579 at $K=K_{0}$, which means that the first-term of (14) is positive. Although the second term of (14) is negative, the first term outweighs it and we have $\widetilde{\pi}_{F, t}^{\prime}\left(c_{S}, t\right)-\widehat{\pi}_{F, t}^{\prime}(\bar{r}, t) \approx 5.5996$. Using $\widehat{\pi}_{F, r}^{\prime}(\bar{r}, t) \approx-2.4783$, we obtain $d \bar{r} / d t \approx-2.2595$. Since $d \bar{r} / d t<\min \left[\lambda_{D}, \lambda_{F}\right]=\lambda_{F} \approx-1.7218$, holding $K$ fixed at $K_{0}, \partial C S\left(K_{0}, t\right) / \partial t>0, \partial C S\left(K_{0}, t\right) / \partial t>0$, and $\partial \pi_{D}\left(K_{0}, t\right) / \partial t<0$ hold.

\section{Appendix A.5. Proof of Lemma 5}

Differentiating $\widehat{\pi}_{F}(\bar{r}, t)=\widetilde{\pi}_{F}\left(c_{S}, t\right)-K$ with respect to $\bar{r}$ and $K$, we have $d \bar{r} / d K=-\left\{\widehat{\pi}_{F, r}^{\prime}(\bar{r}, t)\right\}^{-1}>$ 0 .

\section{Appendix A.6. Proof of Proposition 3}

From (14), $\widetilde{\pi}_{F, t}^{\prime}\left(c_{S}, t_{0}\right)-\widehat{\pi}_{F, t}^{\prime}\left(\bar{r}, t_{0}\right)=0$ if $\bar{r}=c_{S}$. Besides that, $\widehat{\pi}_{F, r}^{\prime}\left(\bar{r}, t_{0}\right)<0$ holds for all $\bar{r} \geq c_{S}$. Hence, by (13), $d \bar{r} / d t=0$ at $\bar{r}=c_{S}$. Furthermore, in view of (A.1), (A.2), (A.3), and (A.4), $\partial \widehat{p}_{i}\left(\bar{r}, t_{0}\right) / \partial \bar{r}>0$ and $\partial \widehat{p}_{i}\left(\bar{r}, t_{0}\right) / \partial t>0$ are satisfied for all $\bar{r} \geq c_{S}$ and thereby $\lambda_{i}<0$ always holds. Consequently, we can always find a unique value $\widehat{r}>0$ such that $d \bar{r} / d t=\max \left[\lambda_{D}, \lambda_{F}\right]$ holds for $\bar{r}=\widehat{r}$ and $d \bar{r} / d t>\max \left[\lambda_{D}, \lambda_{F}\right]$ holds for all $\bar{r}<\widehat{r}$. By Lemma 5 , a reduction of $K$ decreases $\bar{r}$, which implies that we can always find $\widehat{K}>0$ such that $d \bar{r} / d t=\max \left[\lambda_{D}, \lambda_{F}\right]$ holds for $K=\widehat{K}$ and $d \bar{r} / d t>\max \left[\lambda_{D}, \lambda_{F}\right]$ holds for all $K<\widehat{K}$.

For $K \leq \widehat{K}$, we have $\partial C S\left(K, t_{0}\right) / \partial t<0$ and $\partial W W\left(K, t_{0}\right) / \partial t<0$, because a tariff reduction never increases the goods prices. If $\partial C S\left(K, t_{0}\right) / \partial t>0$ and $\partial W W\left(K, t_{0}\right) / \partial t>0$ hold for some $K$, then such $K$ must satisfy $K>\widehat{K}$. This means that there exist a unique $K^{C S} \geq \widehat{K}>0$ such 
that $\partial C S\left(K, t_{0}\right) / \partial t<0$ holds for all $K \in\left(0, K^{C S}\right)$, and a unique $K^{W W} \geq \widehat{K}>0$ such that $\partial W W\left(K, t_{0}\right) / \partial t<0$ holds for all $K \in\left(0, K^{W W}\right) .{ }^{39}$

\section{Appendix A.7. Proof of Proposition 4}

By Lemma 5, a reduction of $K$ decreases $\bar{r}$. By Lemma 1, consumer surplus and world welfare are decreasing in $\bar{r}$ holding $t$ fixed. A reduction of $K$ also directly improves world welfare holding $\bar{r}$ fixed. With respect to each firm's profit, since $\widehat{\pi}_{D, r}^{\prime}(r, t)>0$ and $\widehat{\pi}_{F, r}^{\prime}(r, t)<0$ hold, $\widehat{\pi}_{D}(r, t)$ is increasing in $\bar{r}$ and $\widehat{\pi}_{F}(r, t)$ is decreasing in $\bar{r}$ holding $t$ fixed. Consequently, for any given $t$, $C S(K, t), W W(K, t)$, and $\pi_{F}(K, t)$ are decreasing in $K$, while $\pi_{D}(K, t)$ is increasing in $K$.

\section{Appendix A.8. Proof of Proposition 5}

Differentiating (3) and (4) with respect to $p_{i}(i=\{D, F\})$ and $t$, we can verify that

$$
\frac{\partial \widetilde{p}_{D}\left(c_{S}, t\right)}{\partial t}=-\frac{c_{S}}{(1+t) \Omega} \frac{\partial^{2} \pi_{D}}{\partial p_{F} \partial p_{D}} \frac{\partial \widetilde{x}_{F}}{\partial p_{F}}>0
$$

and

$$
\frac{\partial \widetilde{p}_{F}\left(c_{S}, t\right)}{\partial t}=\frac{c_{S}}{(1+t) \Omega} \frac{\partial^{2} \pi_{D}}{\left(\partial p_{D}\right)^{2}} \frac{\partial \widetilde{x}_{F}}{\partial p_{F}}>0
$$

hold.

A change in $t$ affects consumer surplus, world welfare, and firm $D$ 's profit only through tariffinduced changes in $\widetilde{p}_{D}$ and $\widetilde{p}_{F}$. By the envelope theorem, we have $\partial \widetilde{\pi}_{D}\left(c_{S}, t\right) / \partial t=\left[\widetilde{p}_{D}-\right.$ $\left.c_{S}\right]\left(\partial \widetilde{x}_{D} / \partial p_{F}\right)\left(\partial \widetilde{p}_{F} / \partial t\right)>0$. Since consumer surplus and world welfare are decreasing in both $\widetilde{p}_{D}$ and $\widetilde{p}_{F}, \partial C S(K, t) / \partial t<0, \partial \pi_{D}(K, t) / \partial t>0$, and $\partial W W(K, t) / \partial t<0$ hold at $K=0$.

\section{Appendix A.9. The welfare results with $\partial W W\left(p_{D}, p_{F}\right) / \partial p_{i}>0$}

We have considered the case where both $\partial W W\left(p_{D}, p_{F}\right) / \partial p_{D}<0$ and $W W\left(p_{D}, p_{F}\right) / \partial p_{F}<0$ hold in equilibrium. In what follows, we show that the results of the paper remain mostly unchanged when $\Gamma_{i} \equiv \partial W W\left(p_{D}, p_{F}\right) / \partial p_{i}>0(i=D$, or $F)$ holds in equilibrium (see footnote 18). More specifically, results concerning world welfare presented in Lemma 1, Propositions 2 and 4 need some adjustments, while all other results presented in lemmas and propositions remain unchanged.

First, let us consider the FDI equilibrium. By (A.5) and (A.6), we have

$$
\frac{\partial \widetilde{p}_{F}\left(c_{S}, t\right)}{\partial t}-\frac{\partial \widetilde{p}_{D}\left(c_{S}, t\right)}{\partial t}=\frac{c_{S}}{(1+t) \Omega} \frac{\partial \widetilde{x}_{F}}{\partial p_{F}}\left[\frac{\partial^{2} \pi_{D}}{\left(\partial p_{D}\right)^{2}}+\frac{\partial^{2} \pi_{D}}{\partial p_{F} \partial p_{D}}\right]>0 .
$$

Since $\widetilde{p}_{F}\left(c_{S}, 0\right)=\widetilde{p}_{D}\left(c_{S}, 0\right)$ holds, $(23)$ implies that $\widetilde{p}_{F}\left(c_{S}, t\right) \geq \widetilde{p}_{D}\left(c_{S}, t\right)$ always holds. This in turn means that $\Gamma_{F}<0$ always holds, while $\Gamma_{D} \geq 0$ holds if $\frac{\widetilde{p}_{D}\left(c_{S}, t\right)-c_{S}}{\widetilde{p}_{F}\left(c_{S}, t\right)-c_{S}} \leq-\frac{\left(\partial \widetilde{x}_{F} / \partial p_{D}\right)}{\left(\partial \widetilde{x}_{D} / \partial p_{D}\right)}$ and $\Gamma_{D}<0$ holds otherwise. Note that $\Gamma_{D}+\Gamma_{F}<0$ always holds. The effects of an increase in $t$ on world welfare in the FDI equilibrium can be expressed as

$$
\begin{aligned}
\frac{\partial W W\left(\widetilde{p}_{D}, \widetilde{p}_{F}\right)}{\partial t} & =\Gamma_{D} \frac{\partial \widetilde{p}_{D}\left(c_{S}, t\right)}{\partial t}+\Gamma_{F} \frac{\partial \widetilde{p}_{F}\left(c_{S}, t\right)}{\partial t} \\
& =-\Gamma_{D}\left(\frac{\partial \widetilde{p}_{F}\left(c_{S}, t\right)}{\partial t}-\frac{\partial \widetilde{p}_{D}\left(c_{S}, t\right)}{\partial t}\right)+\left(\Gamma_{D}+\Gamma_{F}\right) \frac{\partial \widetilde{p}_{F}\left(c_{S}, t\right)}{\partial t}
\end{aligned}
$$

\footnotetext{
${ }^{39}$ For instance, if we use the same linear demand functions and the same parameters used in the proof of Proposition 2 , we obtain $\widehat{K} \approx 0.74085, K^{C S} \approx 1.35956$, and $K^{W W} \approx 1.43663$.
} 
$>$ From (A.7), even if $\Gamma_{D} \geq 0$ holds, we have $\partial W W\left(\widetilde{p}_{D}, \widetilde{p}_{F}\right) / \partial t<0$. Hence, Proposition 5 remains unchanged when $\partial W W\left(p_{D}, p_{F}\right) / \partial p_{i}>0(i=D$, or $F)$ holds.

Next, we consider the OS equilibrium. In view of (A.1), (A.2), (A.3), and (A.4), we have

$$
\begin{aligned}
& \frac{\partial \widehat{p}_{F}(r, t)}{\partial t}-\frac{\partial \widehat{p}_{D}(r, t)}{\partial t}=\frac{r}{(1+t) \Omega} \frac{\partial \widehat{x}_{F}}{\partial p_{F}}\left[\frac{\partial^{2} \pi_{D}}{\left(\partial p_{D}\right)^{2}}+\frac{\partial^{2} \pi_{D}}{\partial p_{F} \partial p_{D}}\right]>0 \\
& \frac{\partial \widehat{p}_{F}(r, t)}{\partial r}-\frac{\partial \widehat{p}_{D}(r, t)}{\partial r}=\frac{1}{\Omega}\left[\left\{\frac{\partial^{2} \pi_{D}}{\left(\partial p_{D}\right)^{2}}+\frac{\partial^{2} \pi_{D}}{\partial p_{F} \partial p_{D}}\right\} \frac{\partial \widehat{x}_{F}}{\partial p_{F}}+\left\{\frac{\partial^{2} \pi_{F}}{\left(\partial p_{F}\right)^{2}}+\frac{\partial^{2} \pi_{F}}{\partial p_{D} \partial p_{F}}\right\} \frac{\partial \widehat{x}_{F}}{\partial p_{D}}\right] .
\end{aligned}
$$

Under the linear demand system, $x_{i}\left(p_{D}, p_{F}\right)=a-p_{i}+b p_{j}(i, j \in\{D, F\}, i \neq j)$, we can verify that $\partial \widehat{p}_{F}(r, t) / \partial r-\partial \widehat{p}_{D}(r, t) / \partial r>0$ always holds. Under non-linear demands, $\partial \widehat{p}_{F}(r, t) / \partial r-$ $\partial \widehat{p}_{D}(r, t) / \partial r>0$ holds if the magnitude of the cross price effect of good $F, \partial \widehat{x}_{F} / \partial p_{D}$, is sufficiently smaller than that of the own price effect, $\left|\partial \widehat{x}_{F} / \partial p_{F}\right|$.

Suppose $\partial \widehat{p}_{F}(r, t) / \partial r-\partial \widehat{p}_{D}(r, t) / \partial r>0$ holds. Since $\widehat{p}_{D}\left(c_{S}, 0\right)=\widehat{p}_{F}\left(c_{S}, 0\right)$ and $r \geq c_{S}$ hold, (A.8) implies that we have $\widehat{p}_{F}(r, t) \geq \widehat{p}_{D}(r, t)$ in equilibrium. This means that $\Gamma_{F}<0$ always holds while $\Gamma_{D}$ is either positive or negative. Note that $\Gamma_{D}+\Gamma_{F}<0$ always holds. Holding $t$ fixed, the effects of an increase in $r$ on world welfare in the OS equilibrium can be expressed as

$$
\begin{aligned}
\frac{\partial W W\left(\widehat{p}_{D}, \widehat{p}_{F}\right)}{\partial r} & =\Gamma_{D} \frac{\partial \widehat{p}_{D}(r, t)}{\partial r}+\Gamma_{F} \frac{\partial \widehat{p}_{F}(r, t)}{\partial r} \\
& =-\Gamma_{D}\left(\frac{\partial \widehat{p}_{F}(r, t)}{\partial r}-\frac{\partial \widehat{p}_{D}(r, t)}{\partial r}\right)+\left(\Gamma_{D}+\Gamma_{F}\right) \frac{\partial \widehat{p}_{F}(r, t)}{\partial r} .
\end{aligned}
$$

Hence, even if $\Gamma_{D}>0, \partial W W\left(\widehat{p}_{D}, \widehat{p}_{F}\right) / \partial r<0$ always holds in this case. This means that Lemma 1 and Proposition 4 remain unchanged. Alternatively, suppose $\partial \widehat{p}_{F}(r, t) / \partial r-\partial \widehat{p}_{D}(r, t) / \partial r<0$ holds. In this case, $\widehat{p}_{F}(r, t)<\widehat{p}_{D}(r, t)$ may hold if $t$ is small and $r$ is large. If $\widehat{p}_{F}(r, t)<\widehat{p}_{D}(r, t)$ holds, $\Gamma_{D}<0$ holds while $\Gamma_{F}$ can be either positive or negative. Even if $\Gamma_{F}>0$, however, $\Gamma_{D}+\Gamma_{F}<0$ and (A.9) implies that $\partial W W\left(\widehat{p}_{D}, \widehat{p}_{F}\right) / \partial r<0$ always holds. Hence, Lemma 1 and Proposition 4 remain unchanged. Only in the special case where $\partial \widehat{p}_{F}(r, t) / \partial r-\partial \widehat{p}_{D}(r, t) / \partial r<0, \widehat{p}_{F}(r, t)>\widehat{p}_{D}(r, t)$, and $\Gamma_{D}>0$ are satisfied at the same time, the possibility of $\partial W W\left(\widehat{p}_{D}, \widehat{p}_{F}\right) / \partial r>0$ cannot be ruled out and hence $W W(K, t)$ is not necessarily decreasing in $K$ for all $K \in(0, \bar{K}]$, although $W W(K, t)$ is decreasing in $K$ when $K$ is small enough. This means that results concerning world welfare presented in Lemma 1 and Proposition 4 needs some adjustments in this special case.

Regarding Proposition 2, when $\Gamma_{i}>0(i=D$, or $F)$ holds, $\partial W W\left(K_{0}, t\right) / \partial t>0$ may not hold even when $d \bar{r} / d t<\min \left[\lambda_{D}, \lambda_{F}\right]$ holds. However, $\partial W W\left(K_{0}, t\right) / \partial t>0$ holds under a range of parameterizations (for instance, if the parameters are set at $a=10, b=0.99, c_{S}=1, t=0.1$, and $K_{0}=2.5$ under the linear demand system, we have $\Gamma_{D}=0.012444$ and $\left.\partial W W\left(K_{0}, t\right) / \partial t=4.4312\right)$, and in this sense the qualitative nature of Proposition 2 remains unchanged.

We have shown that $\partial W W\left(\widetilde{p}_{D}, \widetilde{p}_{F}\right) / \partial t<0$ holds in the FDI equilibrium irrespective of the sign of $\Gamma_{i}$. If $K$ is sufficiently reduced so that $r$ is sufficiently close to $c_{S}, d \bar{r} / d t$ becomes close to zero and $\widehat{p}_{D}$ and $\widehat{p}_{F}$ approaches $\widetilde{p}_{D}$ and $\widetilde{p}_{F}$ respectively. This means that $\partial W W\left(\widehat{p}_{D}, \widehat{p}_{F}\right) / \partial t \approx$ $\partial W W\left(\widetilde{p}_{D}, \widetilde{p}_{F}\right) / \partial t<0$ holds if $K$ is sufficiently reduced. Hence, Proposition 3 remains unchanged when $\Gamma_{i}>0(i=D$, or $F)$ holds.

\section{References}

Antràs, P., 2003. Firms, contracts, and trade structure. Quarterly Journal of Economics 118, 1375-1418. 
Antràs, P., 2005. Incomplete contracts and the product cycle. American Economic Review 95, 1054-1073.

Antràs, P., Helpman, E., 2004. Global sourcing. Journal of Political Economy 112, 552-580.

Browning, H., Singelmann, J., 1975. The Emergence of a Service Society: Demographic and Sociological Aspects of the Sectoral Transformation of the Labor Force in the USA. National Technical Information Service, Springfield, Va. 22151.

Chen, Y., 2001. On vertical mergers and their competitive effects. RAND Journal of Economics 32, 667-685.

Chen, Y., Ishikawa, J., Yu, Z., 2004. Trade liberalization and strategic outsourcing. Journal of International Economics 63, 419-436.

Djajić, S., Kierzkowski, H., 1989. Goods, services and trade. Economica 56, 83-95.

Feenstra, R., Hanson, G., 2005. Ownership and control in outsourcing to china: Estimating the property-rights theory of the firm. Quarterly Journal of Economics 120, 729-761.

Francois, J., 1990. Trade in producer services and returns due to specialization under monopolistic competition. Canadian Journal of Economics 23, 109-124.

Francois, J., Manchin, M., Norberg, H., 2009. Distribution services and differential producer and consumer price impacts of trade. Mimeographed.

Francois, J., Wooton, I., 2007. Market structure and market access. The World Bank Policy Research Working Paper Series No.4151

Golub, S., 2003. Measures of restrictions on inward foreign direct investment for oecd countries. OECD Economic Studies , 85-116.

Grossman, G., Helpman, E., 2004. Managerial incentives and the international organization of production. Journal of International Economics 63, 237-262.

Helpman, E., 2006. Trade, fdi, and the organization of firms. Journal of Economic Literature 44, 589-630.

Ishikawa, J., Morita, H., Mukunoki, H., 2008. FDI in post-production services and product market competition. Discussion paper available at SSRN: http://ssrn.com/abstract=1140003.

Konan, D., Maskus, K., 2006. Quantifying the impact of services liberalization in a developing country. Journal of Development Economics 81, 142-162.

Markusen, J., 1989. Trade in producer services and in other specialized intermediate inputs. American Economic Review 79, 85-95.

Markusen, J., Rutherford, T., Tarr, D., 2005. Trade and direct investment in producer services and the domestic market for expertise. Canadian Journal of Economics 38, 758-777.

Melitz, M., 2003. The impact of trade on intra-industry reallocations and aggregate industry productivity. Econometrica $71,1695-1725$.

OECD, 2001. New Patterns of Industrial Globalisation: Cross-Border Mergers and Acquisitions and Strategic Alliances. Publications de l'OCDE.

Ohmae, K., 1989. The global logic of strategic alliances. Harvard Business Review 67, 143-154.

Ordover, J., Saloner, G., Salop, S., 1990. Equilibrium vertical foreclosure. American Economic Review 80, $127-142$.

Porter, M., 1985. Competitive Advantage: Creating and Sustaining Superior Performance. New York: The Free Press.

Qiu, L., 2007. Cross-border strategic mergers and alliances. European Economic Review (in press).

Raff, H., von der Ruhr, M., 2001. Foreign direct investment in producer services: Theory and empirical evidence. CESifo Working Paper Series No.598 .

Richardson, M., 2004. Trade policy and access to retail distribution. Review of International Economics 12, 676-688.

Roberts, M., Tybout, J., 1997. What Makes Exports Boom? World Bank Publications.

Roy, M., Marchetti, J., Lim, H., 2007. Services liberalization in the new generation of preferential trade agreements (PTAs): how much further than the gats? World Trade Review 6, 155-192.

Sanna-Randaccio, F., 1996. New protectionism and multinational companies. Journal of International Economics $41,29-51$.

Sharkey, W., Sibley, D., 1993. A Bertrand model of pricing and entry. Economics Letters 41, 199-206.

Spencer, B., 2005. International outsourcing and incomplete contracts. Canadian Journal of Economics 38, 11071135.

Wong, C., Wu, J., Zhang, A., 2006. A model of trade liberalization in services. Review of International Economics $14,148-168$. 
Figure 1

Determination of the service price

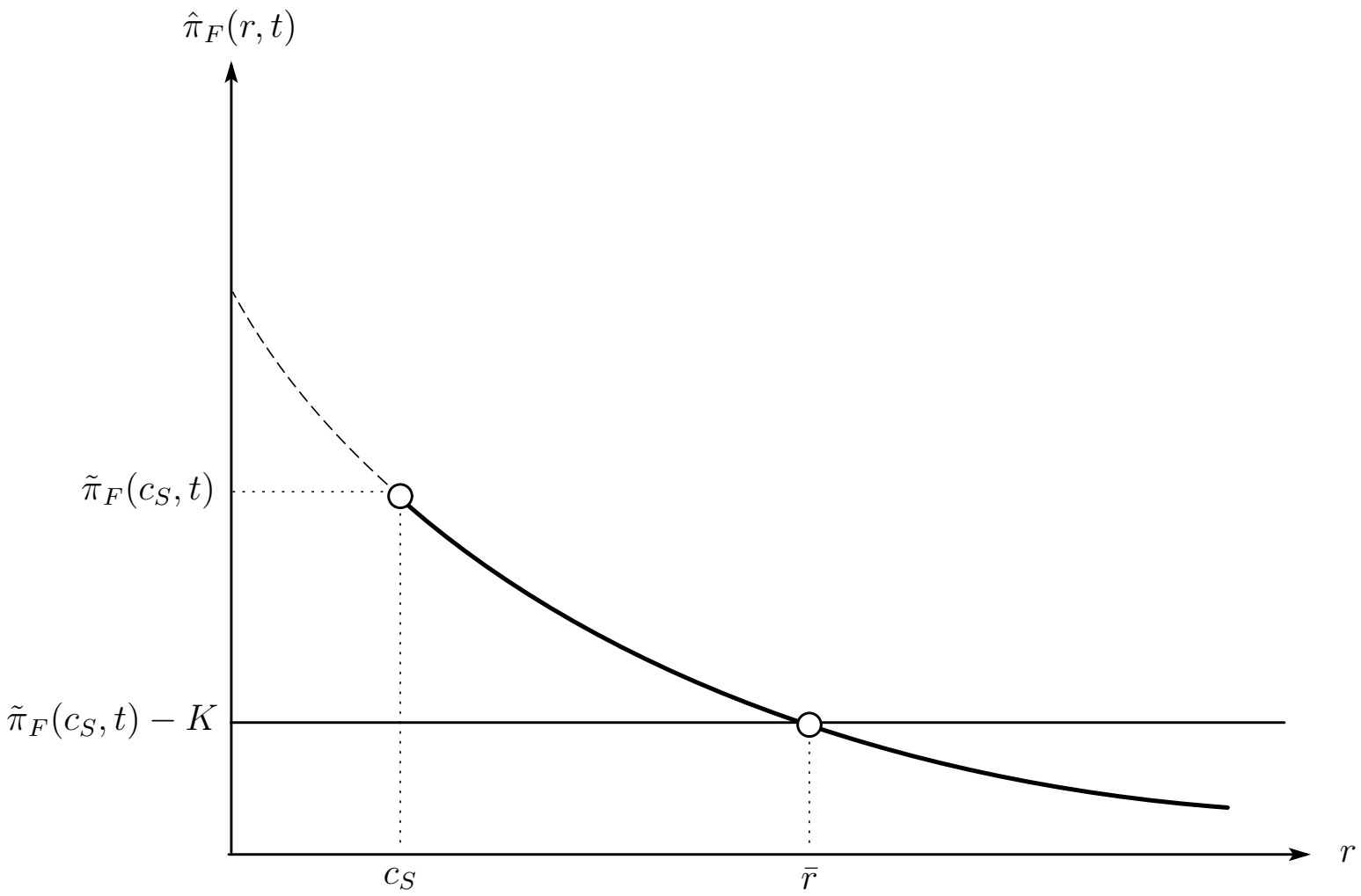


Figure 2

Liberalization of service FDI converts the effects of trade liberalization

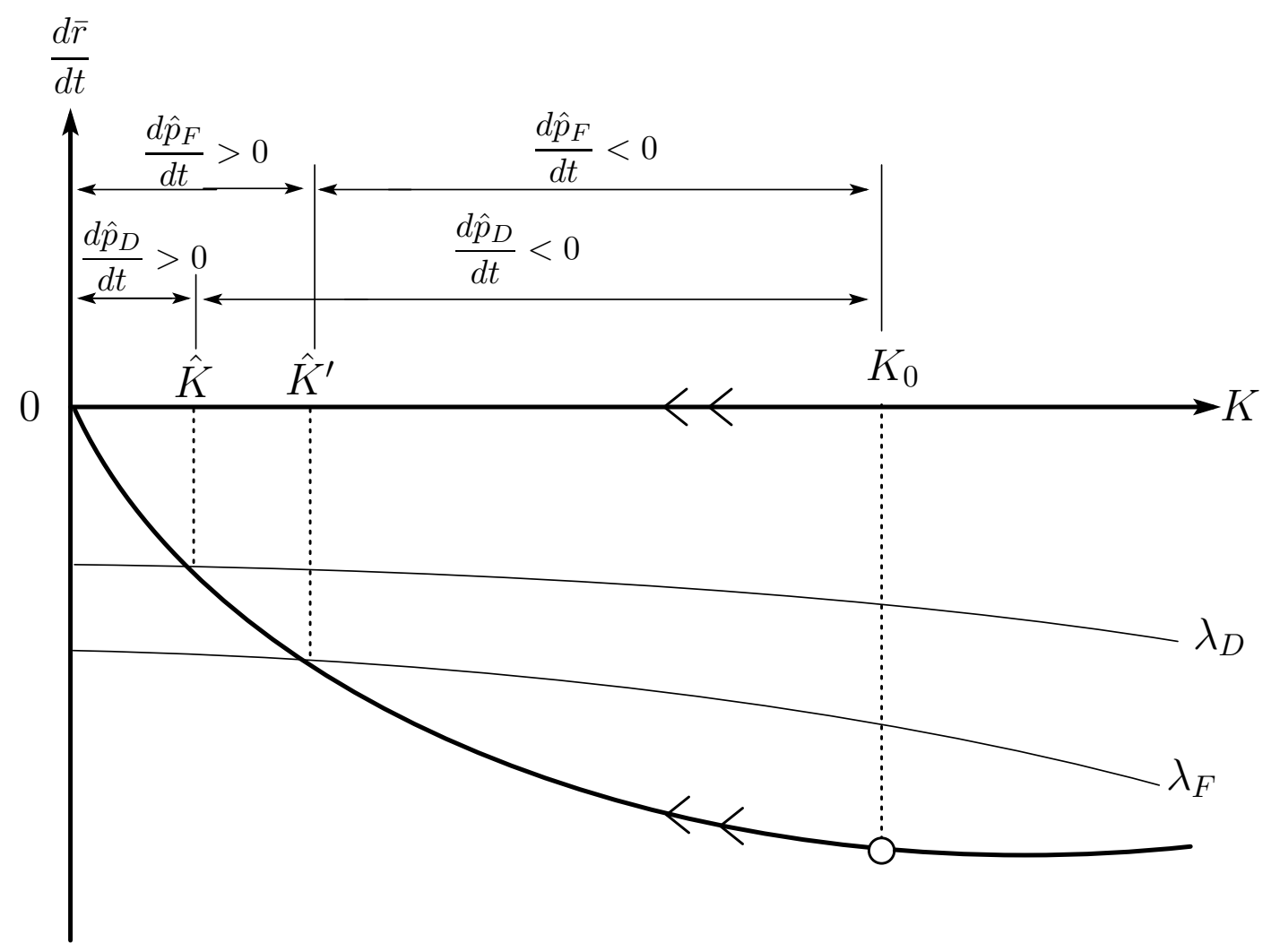

